\title{
A RAINFALL-RUNOFF MODELING PROCEDURE FOR IMPROVING ESTIMATES OF T-YEAR (ANNUAL) FLOODS FOR SMALL DRAINAGE BASINS
}

U.S. GEOLOGICAL SURVEY

Water-Resources Investigations 78-7

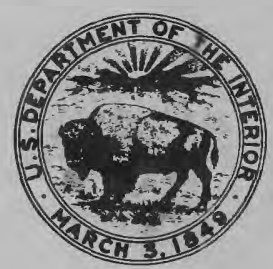




\begin{tabular}{|c|c|c|}
\hline $\begin{array}{l}\text { BIBLIOGRAPHIC DATA } \\
\text { SHEET }\end{array}$ & 2. & 3. Recipicnt's Accession No. \\
\hline \multirow{2}{*}{\multicolumn{2}{|c|}{$\begin{array}{l}\text { 4. Title and Subtitle } \\
\text { A rainfall-runoff modeling procedure for improving estimates of } \\
\text { T-year (annual) floods for small drainage basins }\end{array}$}} & $\begin{array}{l}\text { 5. Report Date } \\
\text { August } 1978\end{array}$ \\
\hline & & 6. \\
\hline \multicolumn{2}{|l|}{$\begin{array}{l}\text { 7. Author(s) } \\
\text { R. W. Lichty and F. Liscum }\end{array}$} & $\begin{array}{l}\text { 8. Petforming Organization Ret } \\
\text { No. USGS/WRI 78-7 }\end{array}$ \\
\hline \multicolumn{2}{|l|}{$\begin{array}{l}\text { 9. Performing O:ganization Name and Address } \\
\text { U.S. Geological Survey } \\
\text { Water Resources Division } \\
\text { Denver Federal Center, Box } 25046 \\
\text { Lakewood, CO } 80225\end{array}$} & $\begin{array}{l}\text { 10. Project/Task/work Unit Nc } \\
\text { 11. Contract/Grant No. }\end{array}$ \\
\hline \multirow{2}{*}{\multicolumn{2}{|c|}{$\begin{array}{l}\text { 12. Sponsoring Organization Namc and Address } \\
\text { U.S. Geological Survey } \\
\text { Water Resources Division } \\
\text { Denver Federal Center, Box } 25046 \\
\text { Lakewood, CO } 80225\end{array}$}} & $\begin{array}{l}\text { 13. Type of Report \& Period } \\
\text { Covered } \\
\text { Final }\end{array}$ \\
\hline & & 14. \\
\hline
\end{tabular}

15. Supplementary Notes

16. Abstracts Maps depicting the influence of a climatic factor, $C$, on the magnitude of synthetic T-year (annual) floods were prepared for a large portion of the eastern United States. The climatic factors were developed by regression analysis of flood data generated using a parametric rainfal1-runoff model and long-term rainfall records. Map estimates of $C$ values and calibrated values of rainfall-runoff model parameters were used as variables in a synthetic T-year flood relation to compute "map-model" flood estimates for 98 small drainage basins in a six-state study area. Improved estimates of T-year floods were computed as a weighted average of the map-model estimate and an observed estimate, with the weights proportional to the relative accuracies of the two estimates. The accuracy of the map-model estimates was appraised by decomposing components of variance into average time-sampling error associated with the observed estimates and average map-mode1 error. Map-model estimates have an accuracy, in terms of equivalent length of observed record, that ranges from 6 years for the 1.25 -year flood up to 30 years for the 50 - and 100 -year flood.

17. Key Words and Document Analysis. 17a. Descriptors

Floods, climatic data, rainfall-runoff relationships, synthetic hydrology, regression analysis, regional analysis

17b. Identifiers/Open-Ended Terms

17c. COSATI Field 'Group

18. Availability Statement

No restriction on distribution

21. No. of Pages 44

22. Price

\begin{tabular}{l} 
19. Security Class (This \\
Report) \\
UNCLASSIEIFD \\
\hline $\begin{array}{l}\text { 20. Secutity Class (This } \\
\text { Page } \\
\text { UNCI.ASSIFIFD }\end{array}$
\end{tabular}

USCOMM-DC ezos. 
A RAINFALL-RUNOFF MODELING PROCEDURE

FOR IMPROVING ESTIMATES OF T-YEAR (ANNUAL)

FLOODS FOR SMALL DRAINAGE BASINS

By R. W. Lichty and F. Liscum

U.S. GEOLOGICAL SURVEY

Water-Resources Investigations 78-7 
UNITED STATES DEPARTMENT OF THE INTERIOR

CECIL D. ANDRUS, Secretary

GEOLOGICAL SURVEY

H. William Menard, Director

For additional information write to:

U.S. Geological Survey

Water Resources Division

Box 25046, Denver Federal Center

Denver, Colorado 80225 
Rainfal1-runoff model-_-

Selection of model calibration sites-C-

Synthesis of annual floods-

Formulation of multiple-regression model-

Regression analysis of synthetic $\mathrm{T}$-year floods--rural model

applications

Effects of imperviousness on synthetic floods-

Single-coefficient relation for synthetic T-year floods---------

Geographic variability of climatic factor, C-C_-

Comparison of observed and map-model flood estimates--

\section{ILLUSTRATIONS}

Figure 1. Schematic outline of model structure, showing components, parameters, variables, and input/output data--

2. Map showing locations of long-term rainfall, and small streams, calibration sites used in study-

3. Relationship between regression constant, $a_{i}$, and regression coefficient, $b_{2}$

4. Relationship between the coefficients $a_{i}$, and $d_{i}$

5. Contour map showing the geographic variation in the 2-year recurrence interval climatic factor, $C_{2}$

6. Contour map showing the geographic variation in the 25-year recurrence interval climatic factor, $C_{25}$

7. Contour map showing the geographic variation in the 100-year recurrence interval climatic factor, $C_{100}$

8. Scatter diagrams of observed and map-model T-year flood estimates-- - - - - -

9. Trends in error-variance components as a function of recurrence interval- 
A RAINFALL-RUNOFF MODELING PROCEDURE FOR IMPROVING ESTIMATES OF T-YEAR (ANNUAL) FLOODS FOR SMALL DRAINAGE BASINS

By R. W. Lichty and F. Liscum

\section{ABSTRACT}

The U.S. Geological Survey rainfall-runoff model is used to synthesize a sample of 550 annual-flood series, that are representative of both rura1- and impervious-area model applications, using data from each of 36 long-term recording rainfall sites. A flood-frequency curve is developed for each annual-flood series, and a single-coefficient, regression relation for the 2-, 25-, and 100-year floods is developed for each one of the rainfall sites-a generalized definition of the model output as a function of the model parameters for each rainfall site. The site-to-site variability in the magnitude of the coefficient that characterizes the synthetic T-year (annual) flood relation is interpreted as reflecting the spatially varying influence of local climatic factors, $C_{i}$, on the results of synthesis. Three contour maps that depict the geographic variability of the climatic factor were prepared. Estimates of the $C_{i}$ values taken from these maps were used in conjunction with fitted rainfall-runoff model parameters and the synthetic T-year flood relation to develop map-model, T-year flood estimates for 98 rural-area streamflow stations located in Missouri, Illinois, Tennessee, Mississippi, Alabama, and Georgia. Comparisons of these flood estimates with those based on observed annual floods show that the map-model estimates are generally lower than the observed estimates for return periods greater than the 2-year recurrence interval. This tendency to underestimate the higher recurrence interval floods was removed by use of an average adjustment factor, $B i$, and the average accuracy of "unbiased", map-model flood estimates was appraised for the test sample of 98 streamflow stations. The accuracy of the map-model estimates increases rapidly with increasing recurrence interval up to the 10-year interval, and then reverses its trend and decreases slowly. The map-model flood estimates are more accurate beyond the 10-year recurrence interval than observed estimates based on a harmonic-mean record length of 13.2 years.

Improved T-year flood estimates were computed by weighting observed and map-model estimates, and the accuracy of the improved estimates is appraised as a function of recurrence interval, and in terms of the concept of 
equivalent length of record. The map-model estimating procedure yields an equivalent length of record that ranges from a low of about 6 years for the 1.25-year flood, up to an ultimate, maximum level of about 30 years of data for estimating the 50- and 100-year recurrence interval floods.

\section{INTRODUCTION}

Historically there has been a deficiency of flood data for drainage basins smaller than about 50 square kilometers. Yet the need for such data is great because accurate and timely estimates of the magnitude and frequency of T-year (annual) floods are an important consideration in the design of drainage structures and the delineation of flood-prone areas. The U.S. Geological Survey, in cooperation with various State, Federal, and local agencies, has undertaken an extensive program of data collection to develop a better knowledge of the flood-frequency characteristics of small basins.

Many years of annual flood data are required to reliably define a floodfrequency curve. One procedure utilized by the Survey to estimate T-year floods from short records is rainfall-runoff modeling. Rainfall-runoff modeling is undertaken because relatively long records (60 to 70 years) of rainfall are available at many locations throughout the country. Basically, the concept is that the information contained in the long-term rainfall records can be transformed to streamflow information by synthesizing a long record of annual floods using a calibrated rainfall-runoff model, such as that developed by Dawdy, Lichty, and Bergmann (1972). That is, a short record of observed floods can be effectively lengthened, and the time-sampling error inherent in small samples can be reduced, by the rainfall-runoff modeling process.

A major problem associated with this type of rainfall-runoff model application is the lack of long-term rainfall data at each site for which modelextended data are required or desired. The goal of reducing time-sampling error in observed flood-frequency estimates can, in general, only be achieved if a method of integrating and transferring information from the available long-term rainfall sites is incorporated in the modeling procedure. In addition, the accuracy of the transfer mechanism must be appraised to allow a meaningful weighting of observed and modeled flood-frequency estimates in relation to their respective accuracies.

This report describes and evaluates a procedure for computing improved estimates of $\mathrm{T}$-year floods that incorporates a rainfall information transfer mechanism in the form of three maps, and a generalized definition of synthetic T-year flood potential as a function of fitted rainfall-runoff model parameters. The maps depict the geographic variability of a coefficient, $C_{i}$, $(i=2-, 25-$, and 100-year recurrence intervals) that reflects the influence of local climatic factors on synthetic T-year floods. The climatic factors are derived by analysis of the results of synthesis using the rainfall-runoff model in conjunction with long-term rainfall data and an average daily pattern of potential evapotranspiration. 
The generalized definition of synthetic T-year floods facilitates the computation of a "map-model", flood-frequency curve at smal1-basin calibration sites by using map estimates of the climatic factor, $C_{i}$, and fitted rainfal1runoff mode1 parameters. Comparisons of observed and map-mode1, T-year, flood estimates, for a sample of 98 rural-area calibration sites located in Missouri, Illinois, Tennessee, Mississippi, Alabama, and Georgia, show that the mapmodel estimates are generally too low in relation to observed estimates for recurrence intervals greater than the 2-year or median flood. Average bias correction factors, $B_{i}$, are determined for the 2-, 25-, and 100-year recurrence intervals, and the accuracy of "unbiased", map-model, T-year flood estimates is evaluated by decomposing error variance components into average error variance of the map-model estimates, and average time-sampling error variance associated with the observed flood estimates.

The procedure for computing an improved T-year flood estimate involves the computation of a weighted average of the observed and map-model estimates. The weighting factors are developed for each calibration site as a function of the time-sampling variance of the observed estimate and the average variance of the map-model estimate.

\section{METHODS OF STUDY}

Many flood-frequency investigations have successfully utilized multipleregression analysis to explain the variability in the occurrence of floods, and to provide a generalized definition of the magnitude of T-year floods as a function of drainage-basin characteristics. For example, Benson (1962, 1964) and Thomas and Benson (1970) demonstrated that observed T-year flood estimates may be related to various topographic and climatic factors (basin characteristics) in the form

$$
\hat{y}=a X_{1}^{b_{1}}{ }_{X_{2}}^{b_{2}}, \ldots x_{n}^{b_{n}}
$$

where

$$
\hat{Y}=\text { predicted value of } T \text {-year flood, }
$$

$X_{1}$ to $X_{n}=$ basin and climatic characteristics (drainage area, slope,
precipitation intensity, and so forth),

$a=$ regression constant, and

$b_{1}$ to $b_{n}=$ regression coefficients.

In an analogous manner, multiple-regression analysis should be useful in explaining the variability of synthetic floods derived by rainfall-runoff modeling using a particular long-term rainfall record. It should also provide 
a generalized definition of the magnitude of synthetic T-year floods, as a function of rainfall-runoff model parameters, for each individual rainfall site. Study and interpretation of the regression results should provide insight into how the influence of climate manifests itself in the magnitude, interaction and geographic variability of the regression constant and coefficients, $a, b_{1}, b_{2}, \ldots b_{n}$.

\section{Rainfal1-Runoff Mode1}

The rainfal1-runoff model used in this study is a simplified, conceptual, bulk-parameter, mathematical model of the surface-runoff component of floodhydrograph response to storm rainfal1. (Dawdy, and others, 1972.) The contribution of base flow, interflow, and quick return flow to the flood hydrograph are not considered because they are generally negligible. The model deals with three components of the hydrologic cycle--antecedent soil moisture, storm infiltration, and surface-runoff routing. The first component simulates soil-moisture conditions at the onset of a storm period through the application of moisture-accounting techniques on a daily cycle. Estimates of daily rainfall, evaporation, and initial values of the moisture storage variables are elements used in this component. The second component involves an infiltration equation (Philip, 1954) and certain assumptions by which rainfall excess is determined on a 5-minute accounting cycle from storm-period rainfall. Storm rainfal1 may be defined at 5-, 10-, 15-, 30-, or 60-minute intervals, but 1oss rates and rainfall excess amounts are computed at 5-minute intervals. The third component transforms the simulated time pattern of rainfall excess into a flood hydrograph by translation and linear storage attenuation (Clark, 1945.) The structure of the model is shown in figure 1 (following). Table 1 (page 35) summarizes the model parameters and their application in the modeling process; (a11 tables are at end of report). For a more complete description of the model see Dawdy, Lichty, and Bergmann (1972).

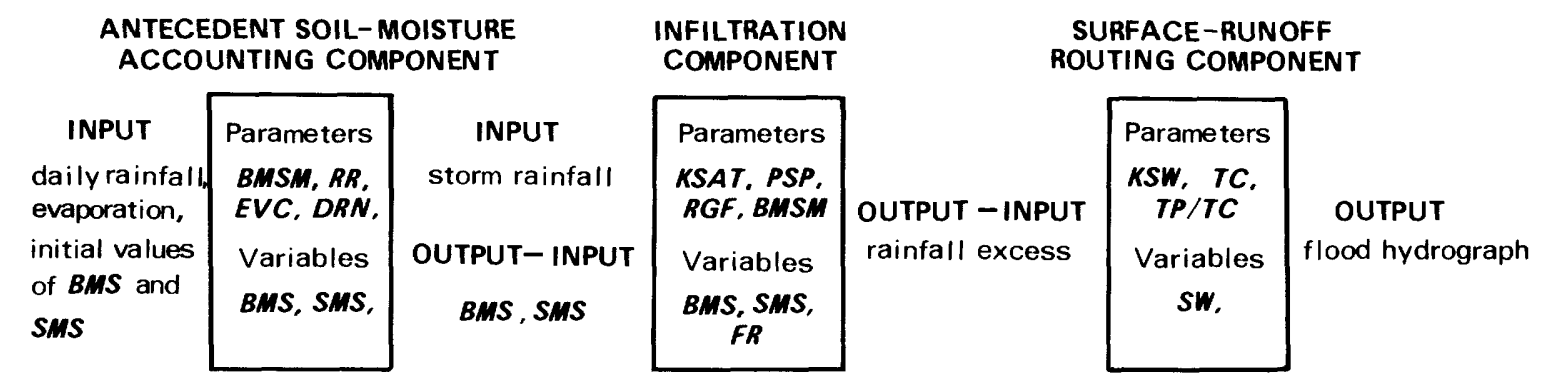

FIGURE 1:- Schematic outline of the rainfall-runoff model structure, showing components, parameters, variables, and input-output data, flow is left to right. 
The model and an automated procedure for determining optimal parameter values are included in both FORTRAN and PL/1 computer language programs, described by Carrigan (1973). The programs provide for the input and storage of observed data, the simulation of flood hydrograph response to storm rainfa11, and multistep optimization of model parameters to minimize the error between observed and computed flood peaks.

\section{Selection of Model Calibration Sites}

Model calibration results were assembled for sites in Missouri (Hauth, 1974), Alabama (McCain, 1974), Mississippi (Colson and Hudson, 1976), Georgia (Golden and Price, 1976), Tennessee (Wibben, 1976), and Illinois (Curtis, 1977), and a sample of 99 streamflow stations was selected to give an approximately uniform spatial configuration of station locations over the six-state study area (fig. 2). Calibrations were rerun for sites in Missouri, Tennessee, Alabama, and Georgia, to conform to a restrictive set of calibration guidelines, as follows, assign $R R, E V C, D R N$, and TP/TC (table 1). Recalibration results were essentially the same as those initially reported. The sample was divided into two sets: 50 stations for development of synthetic annualflood data, and the remainder withheld, to be included in the development and evaluation of a map-model estimating procedure.

\section{Synthesis of Annual Floods}

At each of the 36 long-term rainfall sites shown in figure 2, and described in table 2, synthetic data were developed to relate rainfal1-runoff model estimates of T-year floods to the parameters of the model. This was accomplished by generating a sample of 50 synthetic, annual-flood series using data from each rainfall site. The synthetic data sets were developed using calibrated model parameters for a representative sample of 50 basins shown in figure 2, and described in table 3. Replicate synthesis was performed at each rainfall site using the same sample of fitted model parameters, resulting in a total of 1,800 synthetic, annual-flood series (50 parameter sets by 36 rainfall records) that are representative of model applications in small rural basins.

Additional flood series were generated in an analogous manner to study the effects of "urban development" on synthetic flood characteristics. Ten levels of imperviousness $(5,10, \ldots, 50$ percent) were assigned to each model/rain-gage application, resulting in a total of 18,000 (50 by 36 model/rain-gage applications by 10 levels of imperviousness) synthetic, annualflood series with impervious effects. The generation of rainfall excess from impervious surfaces was modeled by a simple threshold concept that required the retention of 0.05 inch of storm rainfall before the surface becomes 100 percent effective in producing runoff. Retention capacity was allowed to recover by evaporation during periods of no rainfall. 


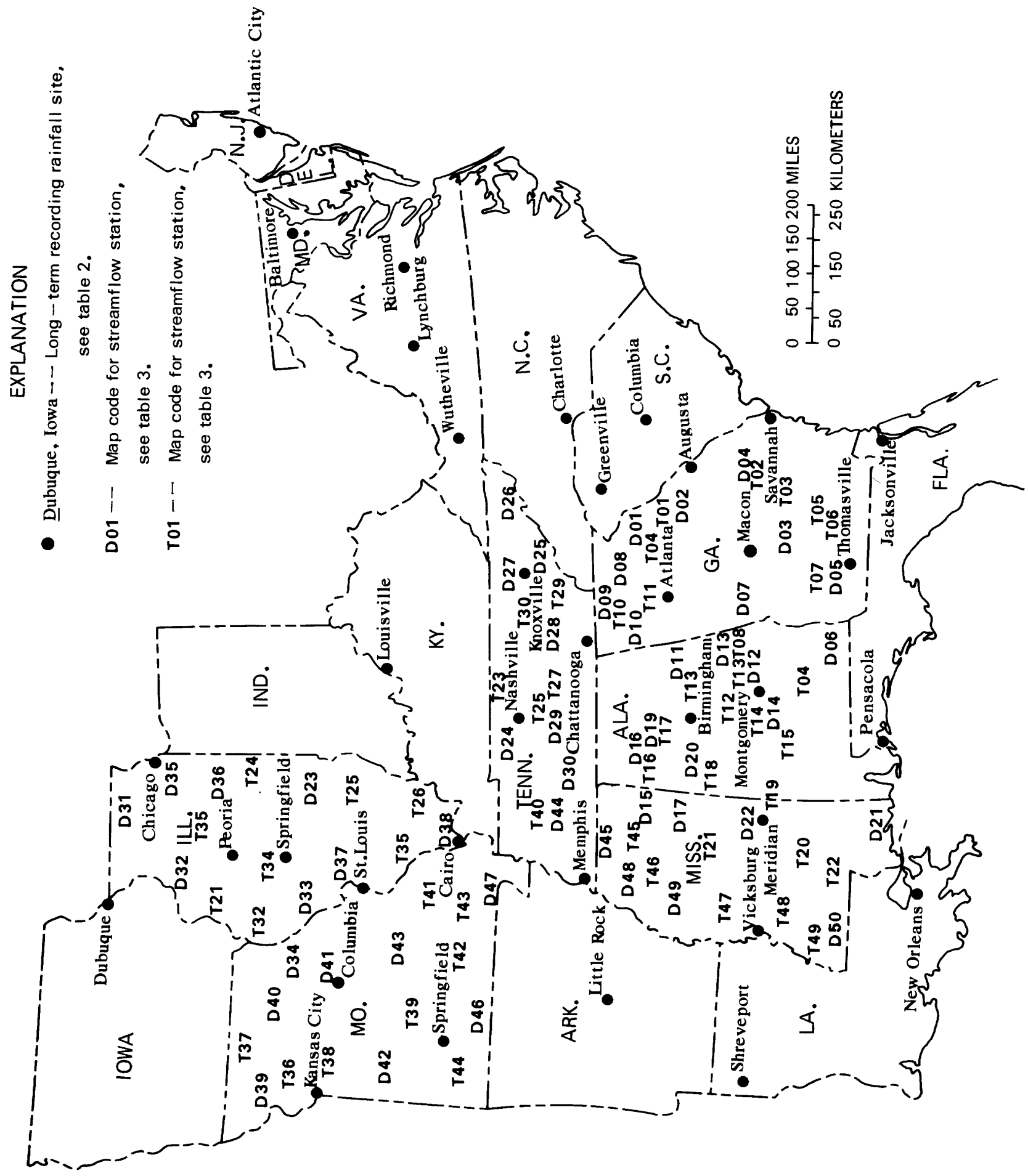


The log-Pearson Type III distribution, fit by the method of moments, was used to quantify synthetic T-year flood estimates for each model/rain-gage application.

Formulation of Multiple-Regression Model

The rainfall-runoff model simulates a flood hydrograph and associated peak discharge rate by routing a volume of runoff (pattern of rainfall excess) with a model of an instantaneous unit hydrograph, IUH. With this two-phase operation as a guide, two factors were defined--an infiltration factor, $F$, and a hydrograph shape factor, $L$, that characterize the separate effects of model parameters on the volume of runoff and the shape of the $I U H$. Using these two factors as independent variables, a multiple-regression model was formulated to give a generalized definition of synthetic T-year floods (dependent variable) for each rainfall record, as follows,

$$
\hat{q}_{i, j}=a_{i}{ }^{L_{j}}{ }^{b_{F_{j}}}{ }^{b_{2 i}} \text {, }
$$

where

$$
\begin{aligned}
& \hat{q}_{i, j}=\text { predicted value of standardized, synthetic discharge in cubic } \\
& \text { feet per second per square mile for the } i \text {-th recurrence } \\
& \text { interval, } i=2-, 25-\text {, and 100-years, for the } j \text {-th model } \\
& \text { application, } j=1 \text { to } 50 \text { (drainage area is a scalar multiplier } \\
& \text { in rainfal1-runoff model computations; therefore, the results } \\
& \text { were "standardized" by dividing by the drainage area), } \\
& L_{j}=1 \mathrm{ag} \text { of } I U H \text {, see table } 3 \text {, } \\
& F_{j}=\text { infiltration factor, see table } 3 \text {, } \\
& a_{i}=\text { regression constant for } i-\text { th recurrence interval, and } \\
& b_{1 i}, b_{2 i}=\text { regression coefficients for } i \text {-th recurrence interval. }
\end{aligned}
$$

Lag time has been successfully used as a hydrograph shape factor in observed flood-frequency studies by Carter (1961), Martens (1968), and Anderson (1970), and was selected for use in the analysis of synthetic floodfrequency characteristics. The lag, $L$, of the rainfall-runoff model routing component is the expected value of the distribution of arrival times of the ordinates of the IUH. According to Kraijenhoff van de Leur (1966), the lag of the rainfall-runoff model $I U H$ is a linear combination of the 
reservoir recession coefficient, $K S W$, and the time base, $T C$, of the isosceles translation hydrograph

$$
L=K S W+0.5 T C,
$$

where

$L=1 \mathrm{ag}$ of instantaneous unit-hydrograph, in hours,

$K S W=1$ inear reservoir recession coefficient, in hours, and

$T C=$ time base of isosceles translation hydrograph, in hours.

An infiltration factor, $F$, was formulated to characterize the interactive effects of infiltration component parameters on the volume of storm runoff. The factor is defined as the infiltration capacity associated with an antecedent soil-moisture condition of 85 percent of field capacity, $B S M / B M S M=0.85$, and accumulated storm infiltration of two inches, $S M S=2$. These conditioning values of $S M S$ and $B M S / B M S M$ were estimated by analysis of the value and sensitivity of the standard error of estimate for trial regressions using various combinations of these values. The form of infiltration equation used in rainfall-runoff model computations is

$$
F R=K S A T[1.0+(P S P / S M S) \cdot(R G F \cdot(1.0-B M S / B M S M)+(B S M / B M S M))],
$$

and substitution of the conditioning values of $S M S=2$, and $B M S / B M S M=0.85$, yields the formulation for $F$ as

$$
F=\operatorname{KSAT}[1.0+0.5 \cdot \operatorname{PSP} \cdot(0.15 R G F+0.85)]
$$

\section{Regression Analysis of Synthetic T-Year Floods--Rural Model Applications}

For each rainfall site, the synthetic T-year floods representative of the rural mode1 applications (sample of 50 ) were related to rainfall-runof $f$ model parameters by use of equation 2 . The magnitude of the regression constants anc coefficients will reflect the influence of climate as it is imbedded in the data used for synthesis. The rainfall-runoff model did not change from rainfall site to rainfall site, nor did the sample of model parameters. The only thing that influences the variability in output, from rainfall site to rainfall site, is the difference in input data--a reflection of climate. 
The multiple-regression analyses show an increase in the accuracy of the relations with increasing recurrence interval, and also in a north-to-south direction (table 4). This is due to a decrease in the variability, and an increase in the average level of modeled antecedent soil-moisture associated with increasing recurrence interval, and with higher rainfall in the South. The regression model does not explicitly include the influence of the variability of the parameter $B M S M$, and to a certain degree, the affect of its variability on synthesis results is attenuated by high rainfall, both northto-south and with increasing recurrence interval.

The regression coefficient, $b_{1}$, which describes the influence of hydrograph shape on T-year floods, shows low variability both geographically and with increasing recurrence interval. This is a reflection of the linearity of the rainfal1-runoff model routing component--double the volume, double the peak. The regression constant, $a$, and coefficient, $b_{2}$, show strong geographic variability, and are highly related as shown in figure 3. This empirical relationship indicates that the rainfall-runoff model is "well behaved" in the sense that it performs in a systematic manner when different rainfall records are used to synthesize annual floods. More importantly, the relationship suggests that the regression model could be modified by expressing the coefficient $b_{2}$ a function of $a_{i}$, and thereby eliminate the need to define the geographic variability of $b_{2_{i}}$. That is,

$$
b_{i}=f\left(a_{i}\right)=\gamma \log a_{i}+\beta
$$

where the parameters $\gamma=0.41$, and $\beta=-1.39$, describe the line approximating the relationship indicated in figure 3. In addition, the low variability of the regression coefficient, $b_{1}$, (coefficient of variation $=0.13$ ) suggests that it could be assigned its mean value, $\bar{b}_{1}=-0.69$, with little loss of accuracy.

A second, "constrained" regression model was formulated as

$$
\hat{q}_{i, j}=a_{i} L_{F}^{-0.69 f\left(a_{i}\right)}
$$

and the single coefficient, $\alpha_{i}$, was determined for each recurrence interval, to minimize the sum of the squares of the difference in the logarithms of

flow by a direct search procedure; that is, $\operatorname{Min} \sum_{j=1}^{50}\left(\log \hat{q}_{i, j}-\log q_{i, j}\right)^{2}$. 


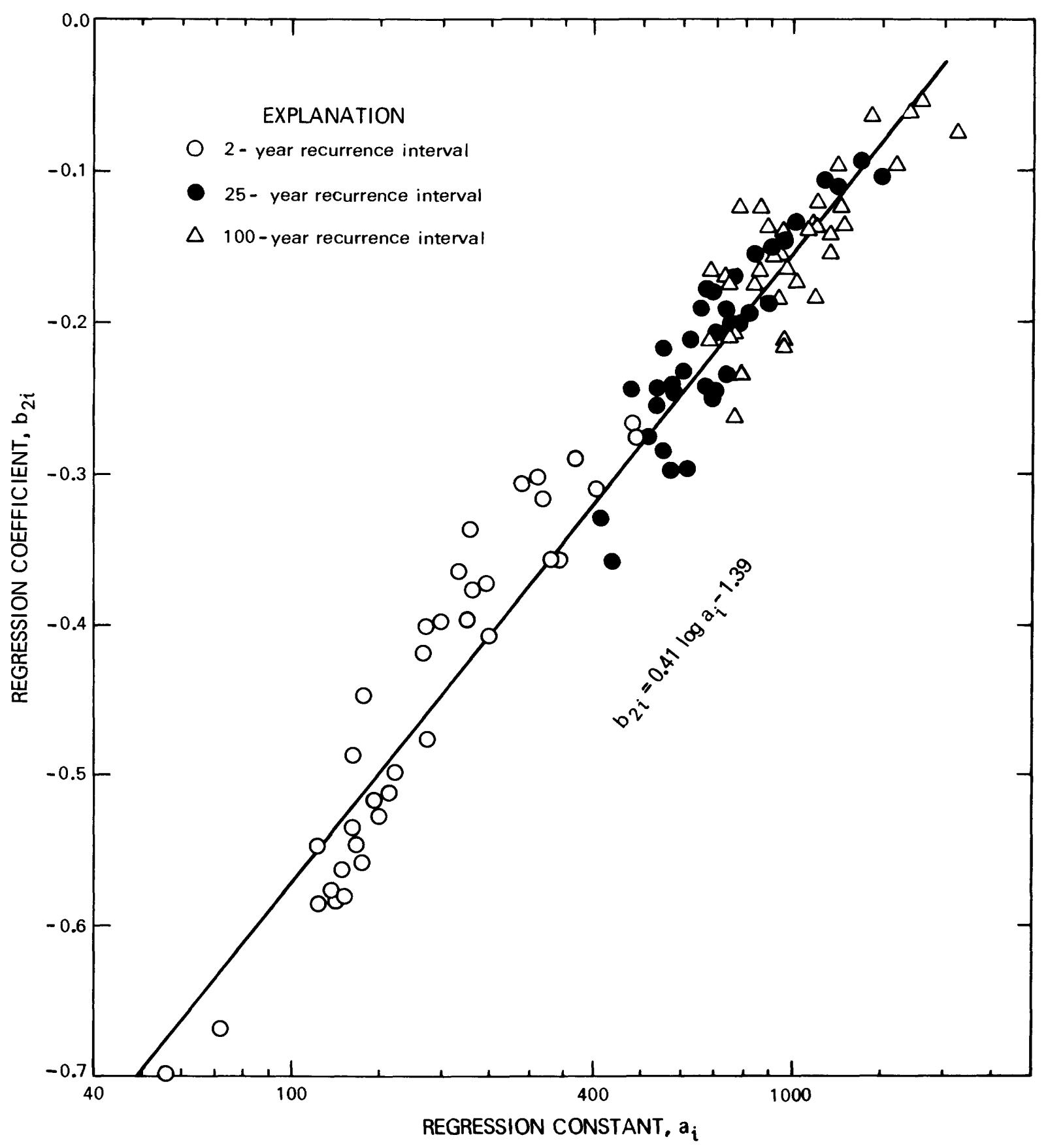

Figure 3.-- Relation between regression constant, $a_{i}$, and regression coefficient, $b_{2 i}$. 
The results shown in table 5 indicate that the constrained, single-coefficient regression model is a reasonable substitute for the initial multipleregression model, with only slightly higher standard errors of estimate and similar trends in the accuracy of the relations as a function of recurrence interval and geographic location.

\section{Effects of Imperviousness on Synthetc Floods}

The unit-hydrograph concept of linearity, that relates flow rate to volume of runoff (double the volume, double the peak), was used to formulate a model to quantify the effect of the increased volume of runoff from impervious areas on synthetic T-year floods. If we neglect the difference in the time patterns of rainfall excess generated from pervious and impervious contributing areas, then

$$
\frac{P_{I}}{P} \simeq \frac{V_{I}}{V} \simeq \frac{V(1-I)+R \cdot I}{V},
$$

where

$$
\begin{aligned}
P_{I} & =\text { peak with impervious area contribution, } \\
P & =\text { peak without impervious area contribution, } \\
V_{I} & =\text { volume runoff with impervious area contribution, } \\
V & =\text { volume runoff without impervious area contribution, } \\
I & =\text { proportion of drainage area with impervious surface, } \\
R & =\text { volume of storm rainfall. }
\end{aligned}
$$

The ratio on the right-hand side of the approximation is analogous to the "coefficient of imperviousness", K, introduced by Carter (1961) to describe the varlability of floods from urban watersheds. By rearranging terms, then

$$
P_{I} \cong P\left[1+I\left(\frac{R}{V}-1\right)\right] .
$$

If we consider that the regression relation without impervious effects indicates that

$$
P=\alpha L^{-0.69_{F} f(\alpha)},
$$


and that

$$
V \propto F^{f} f(\alpha)
$$

and specify

$$
d \propto R,
$$

then a general regression relation for both rural and impervious area model applications may be defined as

$$
\hat{q}_{i, j}=a_{i} L_{j}^{-0.69_{F}} f\left(a_{i}\right)\left[1.0+I_{j}\left(\frac{a_{i}}{F_{j} f\left(a_{i}\right)}-1.0\right)\right] .
$$

The unknown coefficient, $d_{i}$, can be determined by a least-squares fit, just as $a_{i}$ was determined in the analysis of the rural model applications. That is,

$$
\operatorname{Min} \sum_{j=1}^{500}\left(\log \hat{q}_{i, j}-\log q_{i, j}\right)^{2}
$$

by a direct search procedure. A summary of the results of the direct search determinations of the coefficient, $d_{i}$, is shown in table 6 . The standard errors for the 2-year flood relations are consistently lower than those for rural-area model relations. This is because there is substantially less variability in the volumes of runoff and peak flow rates associated with the impervious-area model applications--there are minimum percentages of runoff $(5,10,15, \ldots 50$ percent) from every storm event. Therefore, the adequacy of the infiltration factor, $F$, to characterize runoff volume is not as critical in the regression model formulation for impervious-area applications because there is a "platform" of runoff from every storm event.

\section{Single-Coefficient Relation for Synthetic T-Year Floods}

Similarly, as in the case of the initial rural-regression results, there is a strong relationship between the magnitudes of the regression parameters, in this case, $\alpha_{i}$ and $d_{i}$. This relationship, as shown in figure 4, indicates that two line segments are required to approximate the trend. Using these two approximating relations, equation 13 can be modified to yield a 


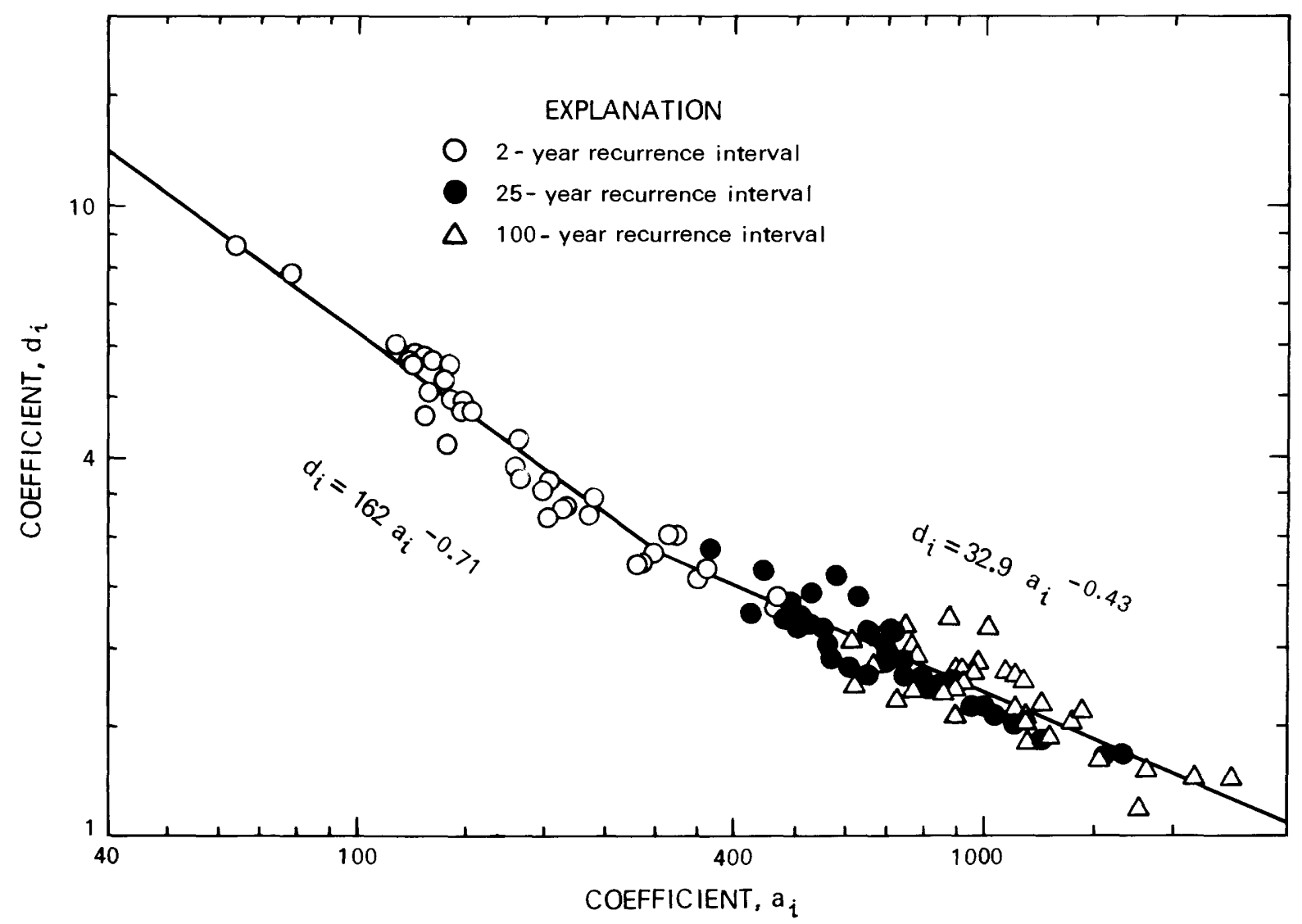

FIGURE 4. Relationship between the coefficients $a_{i}$, and $d_{i}$. 
single-coefficient relation, a generalized definition, that describes both rural- and impervious-area model applications

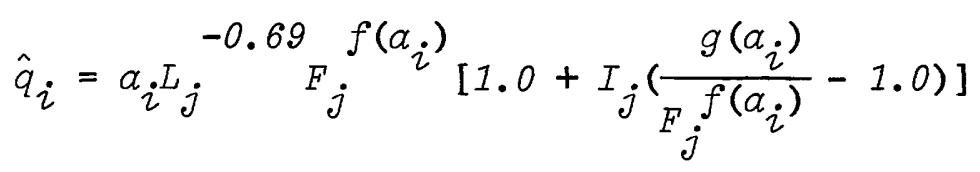

where

$$
f\left(a_{i}\right)=0.41 \log a_{i}-1.39
$$

and

$$
g\left(a_{i}\right)=\left\{\begin{array}{c}
162 a_{i}^{-0.71} \text { for } a_{i} \leq 300, \text { and } \\
32.9 a_{i}^{-0.43} \text { for } a_{i}>300 .
\end{array}\right.
$$

The effectiveness of equation 15 to explain the variability of synthetic T-year floods is summarized in table 7 . These results show that the genera1ized definition is a reasonably accurate relation that describes the results of synthesis for both rural- and impervious-area model applications. The average accuracy of the defining relation is somewhat better for the 25- and 100-year recurrence interval floods than that for 2-year floods, particularly in the North.

\section{Geographic Variability of Climatic Factor, C}

The site-to-site variability in the magnitude of the regression coefficient, $a_{i}$, in equation 15 , is interpreted as reflecting the spatially varying influence of local climatic factors, $C_{i}$, on synthetic flood potential. Contour maps depicting the geographic variability of the climatic factor, $C_{i}$, that is, $\alpha_{i}$, are shown in figures 5, 6, and 7. Estimates of the climatic factor, used in conjunction with the generalized definition of synthetic flood potential, equation 15, offer a means of integrating long-term rainfall information into a procedure to improve T-year flood estimates at rainfall-runoff model calibration sites. The remainder of this report develops and evaluates such a procedure. 


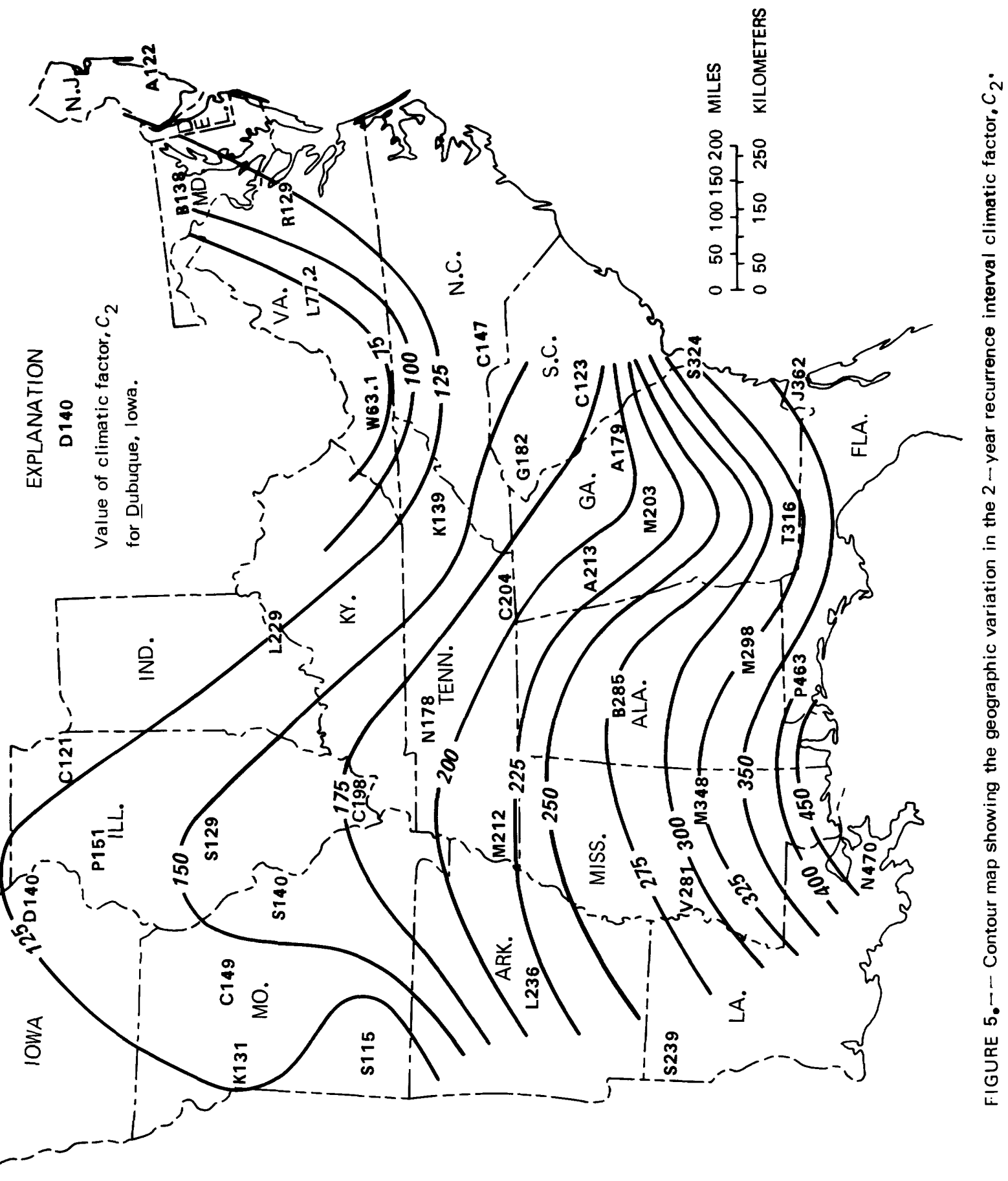




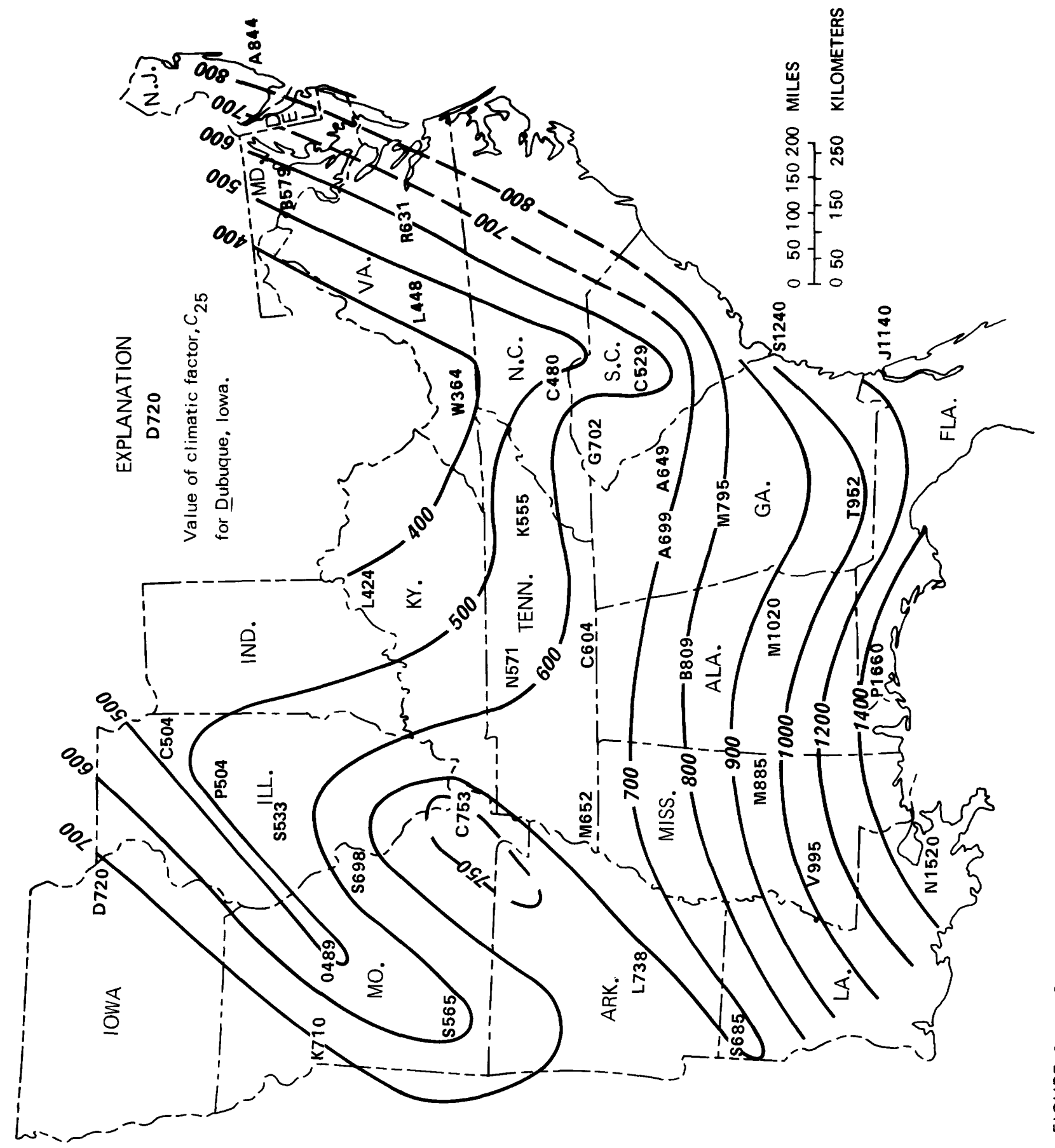




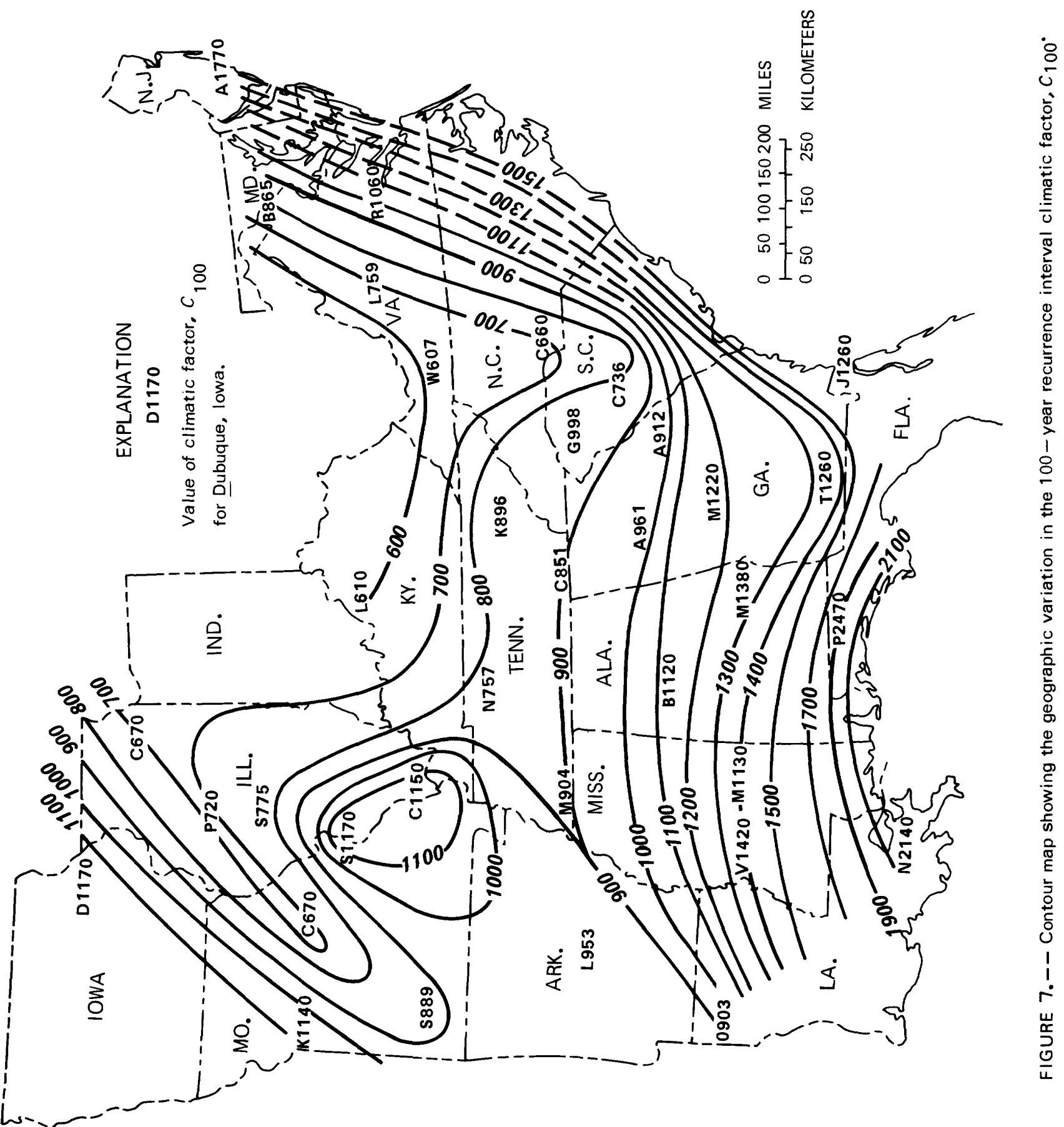


Map-model estimates of the 2-, 25-, and 100-year recurrence interval floods can be computed for rainfall-runoff model calibration sites as follows:

1. Determine values of the climatic factors, $C_{2}, C_{25}$, and $C_{100}$ for the site location using figures 5,6 , and 7 .

2. Compute model lag, $L$, using equation 3 .

3. Compute the infiltration factor, $F$, using equation 5 .

4. Compute the standardized discharge as,

$$
\hat{q}_{i}=C_{i}{ }^{-0.69 f\left(C_{i}\right)}\left[1.0+I\left(\frac{g\left(C_{i}\right)}{f\left(C_{i}\right)}-1.0\right)\right] \text {, }
$$

where

$$
\begin{aligned}
& f\left(C_{i}\right)=0.41 \log C_{i}-1.39, \\
& g\left(C_{i}\right)= \begin{cases}162 C_{i}^{-0.71} C_{i} \leq 300, \text { and } \\
32.9 C_{i}^{-0.43} C_{i}>300 .\end{cases}
\end{aligned}
$$

5. Compute map-model estimates of the T-year floods as,

$$
\hat{Q}_{i}=A \hat{q}_{i},
$$

where

$$
A=\text { drainage area in square miles. }
$$

If it is assumed that the log-Pearson Type III distribution is the underlying population defining the frequency of map-model flood estimates, then estimates of the distribution parameters, that is, estimates of the mean, $\bar{X}$, the standard deviation, $S$, and the skew coefficient, $G$, can be computed by using the values for the 2-, 25-, and 100-year flood magnitudes, and table 
look-up procedures involving percentage points of the distribution as tabulated by Harter (1969), as follows:

1. Use the values for $\hat{Q}_{2}, \hat{Q}_{25}$, and $\hat{Q}_{100}$ as previously determined, to compute the factor $R$, using

$$
R=\frac{\left(\log \hat{Q}_{25}-\log \hat{Q}_{2}\right)}{\left(\log \hat{Q}_{100}-\log \hat{Q}_{2}\right)},
$$

and determine the skew coefficient, $G$, from the following table relating $R$ and $G$.

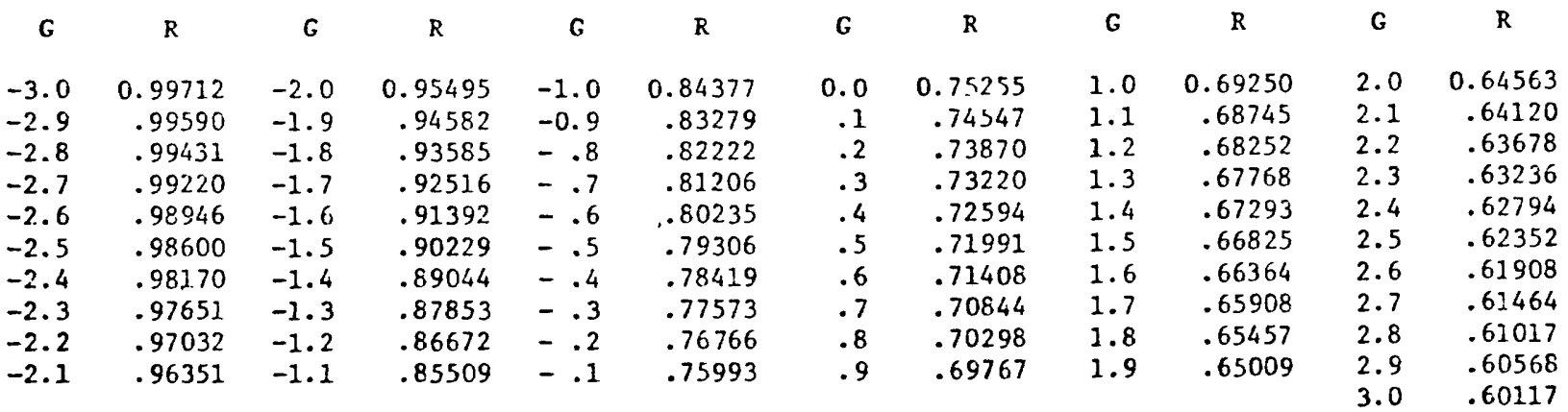

The above table may be extended using the relation

$R=\frac{\left(K_{25}-K_{2}\right)}{\left(K_{100}-K_{2}\right)}$,

where $K_{i}$ is the Pearson Type III deviate (Water Resources Council, 1976, appendix 3.)

2. Compute the standard deviation, $S$, using

$$
S=\frac{\log \left(\hat{Q}_{25} / \hat{Q}_{2}\right)}{D K}
$$


where $D K$ is determined as a function of skew coefficient, $G$, from the following table.

$\begin{array}{cccccccccc}\text { G } & \text { DK } & \text { G } & \text { DK } & \text { G } & \text { DK } & \text { G } & \text { DK } & \text { G } & \text { DK } \\ -3.0 & 0.27031 & -2.0 & 0.65233 & -1.0 & 1.20187 & 0.0 & 1.75069 & 1.0 & 2.20666 \\ -2.9 & .29845 & -1.9 & .70229 & -.9 & 1.25913 & .1 & 1.80124 & 1.1 & 2.24541 \\ -2.8 & .32874 & -1.8 & .75393 & -.8 & 1.31614 & .2 & 1.85081 & 1.2 & 2.28275 \\ -2.7 & .36125 & -1.7 & .80705 & -.7 & 1.37274 & .3 & 1.89942 & 1.3 & 2.31863 \\ -2.6 & .39604 & -1.6 & .86144 & -.6 & 1.42885 & .4 & 1.94690 & 1.4 & 2.35303 \\ -2.5 & .43314 & -1.5 & .91686 & -.5 & 1.48438 & .5 & 1.99324 & 1.5 & 2.38587 \\ -2.4 & .47253 & -1.4 & .97307 & -.4 & 1.53923 & .6 & 2.03841 & 1.6 & 2.41715 \\ -2.3 & .51423 & -1.3 & 1.02988 & -.3 & 1.59336 & .7 & 2.08238 & 1.7 & 2.44681 \\ -2.2 & .55815 & -1.2 & 1.08708 & -.2 & 1.64674 & .8 & 2.12510 & 1.8 & 2.47482 \\ -2.1 & .60423 & -1.1 & 1.14446 & -. .1 & 1.69918 & .9 & 2.16655 & 1.9 & 2.50113\end{array}$

The above table may be extended using the relation

$$
D K=\left(K_{25}-K_{2}\right)
$$

3. Compute the mean, $\bar{X}$, using,

$$
\bar{X}=\log \left(\hat{Q}_{2}\right)-K_{2} S
$$

where $K_{2}$ is a function of skew, $G$, as shown below.

\begin{tabular}{cccccccccc} 
G & \multicolumn{1}{c}{$\mathrm{K}_{2}$} & $\mathrm{G}$ & $\mathrm{K} 2$ & $\mathrm{G}$ & $\mathrm{K} 2$ & $\mathrm{G}$ & $\mathrm{K} 2$ & $\mathrm{G}$ & $\mathrm{K} 2$ \\
-3.0 & 0.39554 & -2.0 & 0.30685 & -1.0 & 0.16397 & 0.0 & 0.00500 & 1.0 & -0.16397 \\
-2.9 & .38991 & -1.9 & .29443 & -0.9 & .14807 & .1 & -.01662 & 1.1 & -.17968 \\
-2.8 & .38353 & -1.8 & .28150 & -.8 & .13199 & .2 & -.03325 & 1.2 & -.19517 \\
-2.7 & .37640 & -1.7 & .26808 & -.7 & .11578 & .3 & -.04993 & 1.3 & -.21040 \\
-2.6 & .36852 & -1.6 & .25422 & -.6 & .09945 & .4 & -.06651 & 1.4 & -.22535 \\
-2.5 & .35992 & -1.5 & .23996 & -.5 & .08302 & .5 & -.08302 & 1.5 & -.23996 \\
-2.4 & .35062 & -1.4 & .22535 & -.4 & .06651 & .6 & -.09945 & 1.6 & -.25422 \\
-2.3 & .34063 & -1.3 & .21040 & -.3 & .04993 & .7 & -.11578 & 1.7 & -.26808 \\
-2.2 & .32999 & -1.2 & .19517 & -.2 & .03325 & .8 & -.13199 & 1.8 & -.28150 \\
-2.1 & .31872 & -1.1 & .17968 & -.1 & .01662 & .9 & -.14807 & 1.9 & -.29443
\end{tabular}

Using these values for the mean, standard deviation, and skew, additional map-model T-year flood estimates can be computed for any desired recurrence interval using the relation

$$
\hat{Q}_{i}=\operatorname{antizog}\left(\bar{X}+K_{i} S\right)
$$




\section{Comparison of Observed and Map-Model Flood Estimates}

Observed and map-model estimates of T-year floods were computed for 98 rainfall-runoff model calibration sites shown in figure 2 , and summarized in table 3. The sample includes 49 of the 50 basins initially selected for use in developing the synthetic flood relations, plus an additional selection of 49 sites to add "strength in numbers"; thus, it was hoped to yield a more meaningful sample for use in comparing observed and map-model flood estimates. Observed T-year flood estimates, $\tilde{Q}_{i}$, were computed using procedures recommended by the Water Resources Council (1976). Map-model flood estimates, $\hat{Q}_{i}$, and associated log-Pearson Type III distribution statistics, $\bar{X}, S$, and $G$ were computed using the methods previously outlined.

Scatter diagrams of observed, $\tilde{Q}_{i}$, versus map-model, $\hat{Q}_{i}$, flood estimates are shown in figure 8. The plots indicate that map-model estimates of the 25- and 100-year floods are generally lower than observed estimates. A comparison of the average values of distribution statistics and T-year floods, in $\log _{10}$ units, is shown below.

\begin{tabular}{|c|c|c|}
\hline Average & Observed & Map-mode \\
\hline $\bar{X}$ & 2.497 & 2.499 \\
\hline$S$ & 0.298 & 0.264 \\
\hline$G$ & -0.109 & -0.261 \\
\hline $\log _{10} Q_{2}$ & 2.502 & 2.512 \\
\hline $\log _{10} Q_{25}$ & 3.004 & 2.929 \\
\hline $\log _{10} Q_{100}$ & 3.161 & 3.049 \\
\hline
\end{tabular}

If it is assumed that on the average, the observed estimates comprise an unbiased time-sample, that is, for each recurrence interval

$$
\frac{1}{98} \sum_{j=1}^{98} \hat{Q}_{j}=\frac{1}{98} \sum_{j=1}^{98} \text { True } Q_{j} \text {, }
$$

then the map-model estimates are apparently biased and should be adjusted to remove the discrepancy in average values shown above. Thus, the generalized definition was modified such that

$$
\text { "unbiased" } \hat{q}_{i}=B_{i} \hat{q}_{i} \text {, }
$$



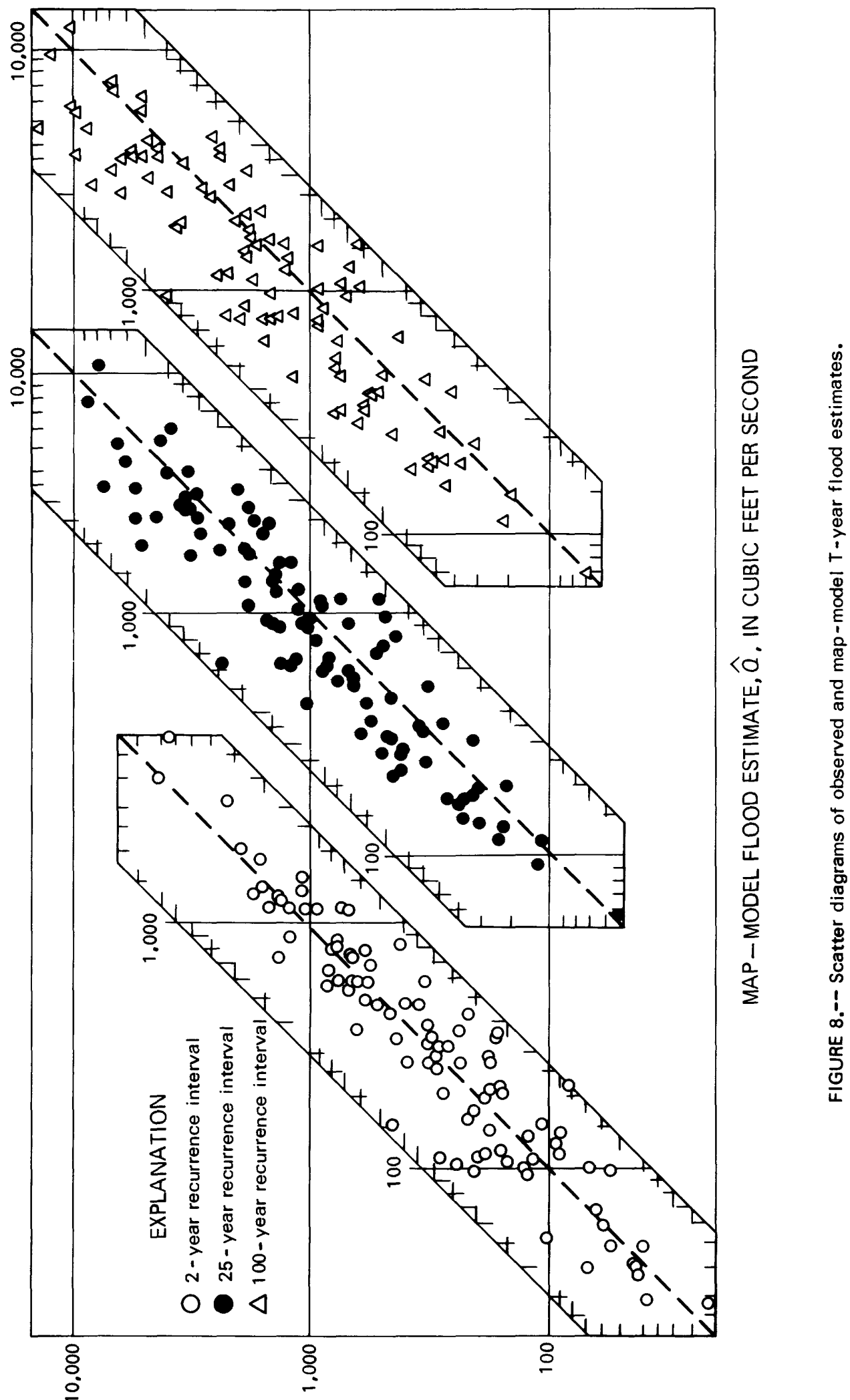

ONOJ 
where

$B_{i}=$ the average map-model bias, $B_{2}=0.98, B_{25}=1.19$, and $B_{100}=1.29$.

ACCURACY AND WEIGHTING OF OBSERVED AND MAP-MODEL T-YEAR FLOODS

We have two essentially independent estimates: the map-model estimate $\hat{Q}_{i, j}$, and the observed estimate $\tilde{Q}_{i, j}$, of the true but unknown T-year flood $Q_{i, j}$. We seek to appraise the accuracy, in some average sense, of the mapmodel estimating procedure, equation 25, and to develop a method of weighting observed and map-model T-year flood estimates. The logarithmic transform of the map-model estimate of the true flood can be written as

$$
\log \hat{Q}_{i, j}=\log Q_{i, j}+\alpha_{i, j},
$$

where $\alpha_{i, j}$ reflects a lumping of error terms including:

(1) error in the rainfall-runoff model (infiltration, routing, etc.),

(2) error in the calibrated model parameters ( $K S W, K S A T$, etc.),

(3) error in the generalized synthetic flood relation, equation 15 ,

(4) error in the maps depicting the influence of climate, $C_{i}$, on synthetic T-year floods, including resolution, time-sampling, and measurement errors, and

(5) error in determination and applicability of the average bias coefficients, $B_{i}$, equation 25 .

If we assume that the expected value of $\alpha_{i, j}$ has mean zero, that is, $\log \hat{Q}_{i, j}$ is unbiased, then the variance of $\alpha_{i, j}$ is

$$
\operatorname{Var}\left[\alpha_{i, j}\right]=E\left[\left(\log \hat{Q}_{i, j}-\log Q_{i, j}\right)^{2}\right]
$$

Similarly, the logarithmic transform of the observed estimate of the true flood is given by

$$
\log \tilde{Q}_{i, j}=\log Q_{i, j}+\varepsilon_{i, j}
$$


If we ignore errors in measurement of discharge and errors in assumptions of the underlying population distribution, then the error term $\varepsilon_{i, j}$, is solely a function of record length, that is, time-sampling error. If we assume that the expected value of $\varepsilon_{i, j}$ has mean zero, that is, $\tilde{Q}_{i, j}$ is unbiased, then the variance of $\varepsilon_{i, j}$ is

$$
\operatorname{Var}\left[\varepsilon_{i, j}\right]=E\left[\left(\log \tilde{Q}_{i, j}-\log Q_{i, j}\right)^{2}\right]
$$

Although both the variance of $\alpha_{i, j}$ and $\varepsilon_{i, j}$ may vary from site-to-site, we seek an overall, average measure of the error variance of the map-model estimating procedure, such as

$$
\overline{\operatorname{Var}}\left[\alpha_{i}\right]=\frac{1}{M} \sum_{j=1}^{M} E\left[\left(\log \hat{Q}_{i, j}-\log Q_{i, j}\right)^{2}\right] ;
$$

in terms of an overall, average measure of the time-sampling error variance of the observed flood estimates, such as

$$
\overline{\operatorname{Var}}\left[\varepsilon_{i}\right]=\frac{1}{M} \sum_{j=1}^{M} E\left[\left(\log \tilde{Q}_{i, j}-\log Q_{i, j}\right)^{2}\right]
$$

A similar average measure of adequacy is found in regression analysis, where the standard error of estimate is taken as a measure of accuracy of regression estimates, even though the variance of any individual estimate is not constant for all values of the independent variables.

One method of obtaining an estimate of $\overline{\operatorname{Var}}\left[\alpha_{i}\right]$ is as follows. The squared differences in $\log \hat{Q}_{i, j}$, and $\log \tilde{Q}_{i, j}$ can be, written as 


$$
\begin{aligned}
\left(\log \hat{Q}_{i, j}-\log \tilde{Q}_{i, j}\right)^{2} & =\left(\log \hat{Q}_{i, j}-\log Q_{i, j}+\log Q_{i, j}-\log \tilde{Q}_{i, j}\right)^{2}, \\
& =\left(\log \hat{Q}_{i, j}-\log Q_{i, j}\right)^{2}+\left(\log \tilde{Q}_{i, j}-\log Q_{i, j}\right)^{2} \\
& -2\left(\log \hat{Q}_{i, j}-\log Q_{i, j}\right)\left(\log \tilde{Q}_{i, j}-\log Q_{i, j}\right) .
\end{aligned}
$$

If the deviations $\left(\log \hat{Q}_{i, j}-\log Q_{i, j}\right)$ and $\left(\log \tilde{Q}_{i, j}-\log Q_{i, j}\right)$ are considered independent in a statistical sense, then by taking expectations and rearranging terms

$$
\begin{array}{r}
E\left[\left(\log \hat{Q}_{i, j}-\log Q_{i, j}\right)^{2}\right]=E\left[\left(\log \hat{Q}_{i, j}-\log \tilde{Q}_{i, j}\right)^{2}\right]- \\
E\left[\left(\log \tilde{Q}_{i, j}-\log Q_{i, j}\right)^{2}\right],
\end{array}
$$

or

$$
\operatorname{Var}\left[\alpha_{i, j}\right]=\operatorname{Var}\left[n_{i, j}\right]-\operatorname{Var}\left[\varepsilon_{i, j}\right]
$$

where

$$
\operatorname{Var}\left[n_{i, j}\right]=E\left[\left(\log \hat{Q}_{i, j}-\log \tilde{Q}_{i, j}\right)^{2}\right]
$$
According to Hardison $(1971), \operatorname{Var}\left[\varepsilon_{i, j}\right]$ can be estimated by $R_{i, j}^{2}{ }_{i j} / N_{j}$, that
is,

$$
\hat{\operatorname{Var}}\left[\varepsilon_{i, j}\right]=R_{i, j}^{2} S_{j}^{2} / N_{j},
$$

where $R_{i, j}^{2}$ is a function of recurrence interval and skew coefficient (Hardison, 1971, table 2), $S^{2}{ }_{j}$ is the sample estimate of the variance of the 
logarithms of observed annual peaks, and $N_{j}$ is the number of observed annual peaks. The quantities $\operatorname{Var}\left[n_{i, j}\right]$ can be directly estimated because both $\hat{Q}_{i, j}$ and $\tilde{Q}_{i, j}$ are available. Thus, averaging over all sites gives an estimate of the average map-model error variance, $\overline{\operatorname{Var}}\left[\alpha_{i}\right]$ as

$$
\overline{V M M}_{i}=\overline{S D}_{i}-\overline{V T}_{i}
$$

where

$$
\overline{S D}_{i}=\frac{1}{M-1} \sum_{j=1}^{M}\left(\log \hat{Q}_{i, j}-\log \tilde{Q}_{i, j}\right)^{2}
$$

and

$$
\overline{V T}_{i}=\frac{1}{M} \sum_{j=1}^{M} R_{i, j}^{2} S_{j}^{2} / N_{j}
$$

The averaging factor, $M-1$, used in the computation of the mean squared 1ogarithmic deviation, $\overline{S D}_{i}$, accounts for a lost degree of freedom associated with the determination of the average bias coefficients, $B_{i}$. A word of caution is necessary when using this method of decomposing variance components. Because $\overline{S D}_{i}$ and $\overline{V T}_{i}$ are computed independent1y of one another, negative values of $\overline{V M M}_{i}$ may result, which are not meaningful.

The preceding formulaton is similar to that developed by Hardison, (1971, equation 3), in his study of prediction error of regression estimates of streamflow characteristics:

$$
V_{S}=V_{R}-(1-\rho) \bar{V}_{T}
$$

where

$V_{S}=$ variance due to space-sampling error; same as model error,

$V_{R}=\begin{gathered}\text { variance of the regression, the square of the standard error of esti- } \\ \text { mate of a regression, }\end{gathered}$

$\rho=$ average interstation correlation coefficient, and

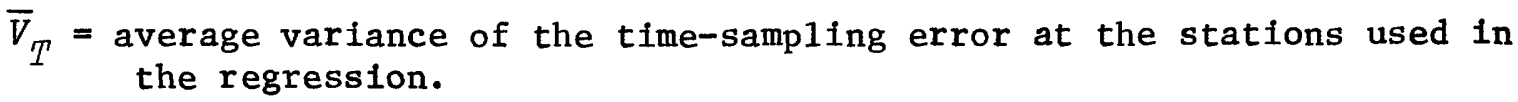


The analogy between the two formulations is as follows: $\overline{V M M}$ is analogous to $V_{S}, \overline{S D}$ is analogous to $V_{R}$ and $\overline{V T}$ is analogous to $\bar{V}_{T}$. The influence of the average interstation correlation, $\rho$, is not accounted for in equation 37 , but its absence is thought to be of minor importance in the present analysis ( $\rho=0.06$ for the 98-station sample).

If it is assumed that the two estimates $\hat{Q}_{i, j}$, and $\tilde{Q}_{i, j}$, are independent and unbiased, then a weighted estimate, $W Q_{i, j}$, can be formed as

$$
W Q_{i, j}=W M M_{i, j} \cdot \hat{Q}_{i, j}+W O_{i, j} \cdot \tilde{Q}_{i, j},
$$

where the map-model weighting factor is

$$
W_{i, j}=\frac{R_{i, j}^{2} S_{j}^{2}{ }_{j}{ }_{j}}{\left(R^{2}{ }_{i, j} S^{2}{ }_{j} / N_{j}+\overline{V M M}_{i}\right)},
$$

and the observed weighting factor is

$$
W O_{i, j}=1-W M M_{i, j}
$$

The variance of the weighted estimate is less than the variance of either the map-model or the observed estimate, and is given by

$$
V W_{i, j}=\frac{\overline{V M M}_{i} \cdot R_{i, j}^{2} S_{j}^{2} / N_{j}}{\left(\overline{V M M}_{i}+R^{2}{ }_{i, j} S_{j}{ }_{j} / N_{j}\right)} .
$$


The average value of the error variance of the weighted estimates may be expressed as

$$
\overline{V W}_{i}=\frac{1}{M} \sum_{j=1}^{M} V W_{i, j}
$$

Equations $37,38,39$, and 45 were used to compute estimates of the average values of the map-model error variance, $\overline{V M M}_{i}$, the time-sampling variance, $\overline{V T}_{i}$, and the error variance of the weighted estimates, $\overline{V W}_{i}$, using observed and map-model flood data for the test sample of 98 rural-area calibration sites. The trends in the values of these variance components are shown as a function of recurrence interval in figure 9. The rapid decrease in the magnitude of the average map-model error variance, from the 1.25-year to the 5-year recurrence interval, is a reflection of the accuracy of the synthetic T-year flood relation, as a function of recurrence interval, and the general accuracy characteristics of the rainfa11-runoff model in the reproduction of sma11magnitude floods.

The synthetic T-year flood relation is less accurate at low recurrence intervals because of the absence of the parameter, $B M S M$, and because the influence of modeled antecedent soil-moisture conditions, $B M S$, and $S M S$, are not explicitly included, nor can they be explicitly included, in the defining relation. $S M S$ and $B M S$ are model variables, not model parameters, and their influence on synthesis results can only be approximated in an average sense, that is, by the "conditioning" values, as previously determined. Modeled antecedent conditions, the influence of $B M S M$, and the adequacy of the infiltration factor, $F$, are less important in explaining synthetic results for the higher recurrence interval floods, because they are attenuated.

Similarly, the influence of real-world, antecedent soi1-moisture conditions are only approximately modeled by the rainfa11-runoff model; they are very important in explaining the variability of flood magnitudes from lower magnitude storms, and resulting generally lower magnitude floods. The rainfal1-runoff model is more accurate in reproducing extreme floods than minor ones. Extreme floods from small basins are extreme for several reasons, but high rainfall intensity/duration dominates. In general, infiltration losses become a less significant part of total rainfall for extreme rainfall events--a threshold effect. The inadequacies in modeled soil-moisture conditions and in the infiltration component tend to be attenuated for the larger events. Storm rainfall assumes a dominant role in determining the output, both in nature and in the rainfall-runoff model abstraction of it, as well as in the regression model abstraction of rainfall-runoff model. 


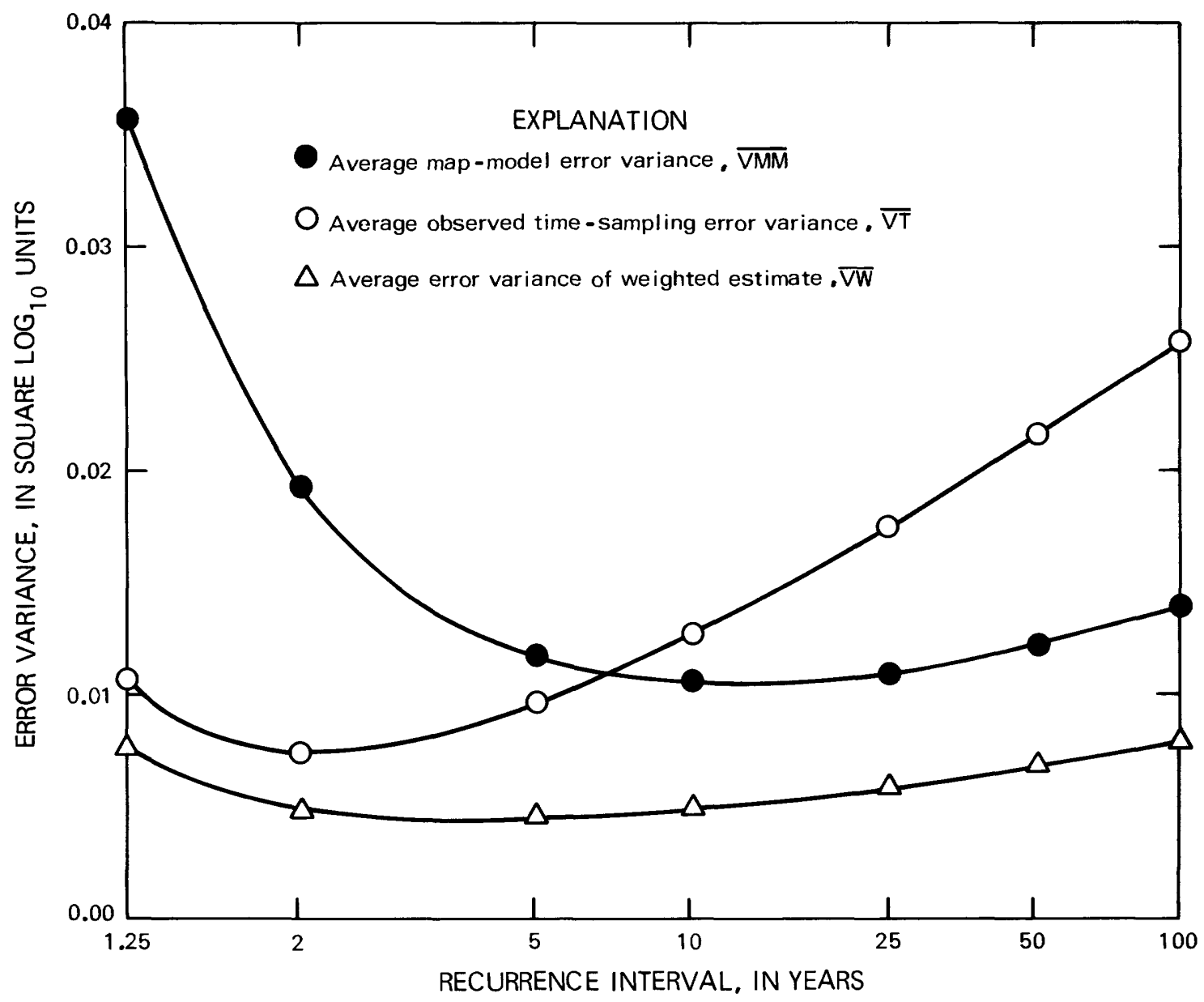

FIGURE 9. -- Trends in error-variance components as a function of recurrence interval. 
The average map-model error variance decreases to a minimum value of about 0.011 squared $10 \mathrm{~g}$ units at the 10-year recurrence interval; then reverses its trend and increases with increasing recurrence interval--a desirable outcome. Without this reversal, the ascribed value of the map-model estimating procedure, in terms of the concept of equivalent-year accuracy (Carter and Benson, 1970), would increase without limit. Logic tells us that there is an upper limit to the amount of information that can be extracted from long-term rainfall records, in this case about 65 years, because that is the average length of record used in the development of the map-model estimating procedure. Obviously, this is an unattainable upper limit, because of the many sources of error inherent in the map-model estimating procedure, including errors in the rainfal1-runoff model, the generalized definitions, and the maps depicting the geographic variability of the inferred effect of climate on synthetic floods.

The trend in the average time-sampling error variance of the observed T-year flood estimates, with a minimum near the 2-year recurrence interval, is a completely predictable statistical outcome. This is because the 2-year flood is less affected by time-sampling error than are the flood levels associated with the tails of the distribution, where the error in sample estimates of the standard deviation and skew coefficient is more influential.

The average error variance of the weighted flood estimates, $\overline{V W}_{i}$, shows the worth of the map-model estimating procedure in relation to observed data estimates that have a harmonic-mean record length of 13.2 years. Note particularly the "flatness" in the trend of $\overline{V W}_{i}$ as a function of recurrence interval, and that the average accuracy of the weighted estimates of the 100-year floods is equivalent to that of the observed data estimates of the 2-year floods. The average accuracy of the weighted T-year flood estimates can be appraised in terms of equivalent-length of observed record using the relation

$$
N E_{i}=N G \frac{\overline{V T}_{i}}{\overline{V W}_{i}}
$$

where

$$
\begin{gathered}
N E_{i}=\text { average equivalent record length of weighted estimates, in years, } \\
N G=\text { harmonic-mean record length of observed annual flood records } \\
\quad(13.2 \text { years }) .
\end{gathered}
$$

The following table shows estimates of the equivalent record lengths of the weighted flood estimates at selected recurrence intervals. 


\section{Recurrence interval}

(years)

$$
1.25
$$

2

5

10

25

50

100
Equivalent record length

(years)

19

20

28

34

40

43

44

These results show a pronounced nonlinearity in equivalent record length as a function of recurrence interval, and also indicate an upper limit to the amount of peak-flow information attainable by the map-model estimating procedure--a gain of about 30 years of record for estimating the higher recurrence interval floods (the 50- and 100-year floods), as compared to a gain of about 6 years of record for estimating the lower recurrence interval floods (the 1.25- and 2-year floods).

\section{SUMMARY AND CONCLUSIONS}

Annual flood series were synthesized for a wide variety of modeled, hydrologic conditions using data from each of 36 long-term recording rainfall sites. A single-coefficient regression relation was developed for each rainfall site to give a generalized definition of synthetic T-year floods as a function of the rainfall-runoff model parameters. The accuracy of the generalized definition increases with an increase in recurrence interval, with an increase in percent impervious area, and in a north-to-south direction. These trends in accuracy are a ramification of the decreasing influence of the variability in infiltration component parameters (KSAT, PSP, RGF, and BMSM) on the increased volumes of runoff and peak discharge rates associated with increasing recurrence interval, increasing impervious area, and also with higher rainfall in the South. The extreme floods are extreme for several reasons, but high rainfall intensity/duration is a necessary condition. For the extreme events, modeled infiltration losses become a less significant part of total rainfall, and the effect of the site-to-site variability in infiltration component parameters is attenuated, as it should be. The site-to-site variability in the routing component parameters, those parameters that define the hydrograph shape factor $L$, assume a dominant role in explaining the reduced variability of extreme flood events. A general maxim for modeling the results of synthesis is "...the higher the variability, the more model data input required to explain the variability." The degree of variability, and thus the ability of the generalized definition to explain that variability, is inversely related to the magnitude of the flood event--it takes less model to explain the reduced variability in extreme floods, and more model to explain the higher variability in small magnitude events. 
The site-to-site variability in the magnitude of the regression coefficient, $a$, that characterizes the generalized T-year flood relation, is a reflection of the spatially varying influence of climate, $C$, on the results of synthesis. Maps depicting the geographic variation in the magnitude of $C$ were prepared and used in conjunction with fitted rainfall-runoff model parameters and the generalized synthetic flood relation to develop map-model, T-year flood estimates for 98 smal1-basin calibration sites. Comparisons of these T-year flood estimates with those based on observed annual floods show that the map-model estimating procedure is biased--the map-model estimates are generally lower than the observed estimates for return periods greater than the 2-year recurrence interval. This tendency for underestimation of the higher recurrence interval events may be attributed to several factors, including:

1. A loss of variance associated with a model smoothing effect, as described by Matalas and Jacobs (1964), and Kirby (1975);

2. The effect of unmodeled, real-world nonlinearities in the transformation of rainfall excess to discharge hydrograph (routing)--a limitation of the unit-hydrograph concept as used in the rainfallrunoff model;

3. Incorrectly modeled nonlinearities in the synthesis of rainfall excess (volume of runoff), due to inadequacies in either anteceddent soil-moisture accounting or infiltration computations;

4. Sampling errors in the long-term rainfall data used for synthesis of annual floods;

5. The use of an average daily pattern of potential evapotranspiration.

Regardless of the particular cause or causes for the tendency to underestimate the higher recurrence interval floods, the bias can be removed in an average sense by using an average adjustment factor, that is, the bias coefficients, $B_{i}$

The average accuracy of unbiased, map-model flood estimates was appraised for the sample of 98 rural-area calibration sites located in a six-state study area. This appraisal shows that the accuracy of the estimates increases rapidly, with increasing recurrence interval up to about the 10-year return perlod, and then reverses its trend and decreases slowly. This pattern of error variance, when compared to that associated with observed flood estimates, indicates that the map-model estimates are more accurate than the observed estimates beyond the 10-year recurrence interval (the harmonic-mean record length of the observed annual flood series is 13.2 years).

Improved T-year flood estimates were developed by computing a weighted average of observed and map-model estimates, and the accuracy of the improved estimates was appraised as a function of recurrence interval and in terms of the concept of equivalent-length of record. The trend in the accuracy of the improved estimates shows that the map-model estimating procedure yields an equivalent-length of observed record that ranges from a low of about 6 years for the 1.25-year flood, up to an ultimate, maximum level of about 30 years of data for estimating the 50- and 100-year recurrence interval floods. 


\section{REFERENCES}

Anderson, D. G., 1970, Effects of urban development on floods in Northern Virginia: U.S. Geological Survey Water-Supply Paper 2001-C, 22 p. Benson, M. A., 1962, Factors influencing the occurrence of floods in a humid region of diverse terrain: U.S. Geological Survey Water-Supply Paper 1580-B, $64 \mathrm{p}$. 1964, Factors affecting the occurrence of floods in the Southwest: U.S. Geological Survey Water-Supply Paper 1580-D, 72 p.

Carrigan, P. H., Jr., 1973, Calibration of U.S. Geological Survey rainfa11runoff model for peak flow synthesis--natural basins: U.S. Geological Survey Computer Contribution, 114 p. Available only from U.S. Department of Commerce, National Technical Information Service (NTIS), Springfield, Va. 22151, accession no. PB-226-217.

Carter, R. W., 1961, Magnitude and frequency of floods in suburban areas, in Short papers in the geological and hydrologic sciences: U.S. Geological Survey Professional Paper 424-B, p. B9-B14.

Carter, R. W., and Benson, M. A., 1970, Concepts for the design of streamflow data programs: U.S. Geological Survey Open-File Report, 33 p.

Clark, C. 0., 1945, Storage and the unit hydrograph: American Society of Civil Engineers Transactions, v. 110, p. 1419-1488.

Colson, B. E., and Hudson, J. W., 1976, Flood frequency of Mississippi streams: U.S. Geological Survey Open-File Report, 34 p.

Curtis, G. W., 1977, Frequency analysis of Illinois floods using observed and synthetic streamflow records: U.S. Geological Survey Water-Resources Investigations 77-104, $32 \mathrm{p}$.

Dawdy, D. R., Lichty, R. W., and Bergmann, J. M., 1972, A rainfa11-runoff model for estimation of flood peaks for small drainage basins: U.S. Geological Survey Professional Paper 506-B, 28 p.

Golden, H. G., and Price, M., 1976, Flood-frequency analysis for small natural streams in Georgia: U.S. Geological Survey Open-File Report 76-511, 77 p.

Hardison, C. H., 1971, Prediction error of regression estimates of streamflow characteristics at ungaged sites: U.S. Geological Survey Professional Paper 750-C, p. C228-C236.

Harter, H. L., 1969, A new table of percentage points of the Pearson Type III distribution: Technometrics, v. 11, no. 1, p. 117-187.

Hauth, L. D., 1974, Model synthesis in frequency analysis of Missouri floods: U.S. Geological Survey Circular 708, 16 p.

Kirby, W., 1975, Model smoothing effect diminishes simulated flood peak variances (abs): American Geophysical Union Transactions, v. 56, no. 6, p. 361 .

Kraijenhoff van de Leur, D. A., 1966, Runoff models with linear elements: in Committee for Hydrological Research T.N.0., Recent trends in hydrograph synthesis: Verslagen En Mededelingen, Commissie Voor Hydrologisch Onderzoek T.N.O. 13, The Hague, p. 31-62.

Martens, L. A., 1968, Flood inundation and effects of urbanization in metropolitan Charlotte, North Carolina: U.S. Geological Survey Water-Supply Paper 1591-C, $60 \mathrm{p}$.

Matalas, N. C,, and Jacobs, B., 1964, A correlation procedure for augmenting hydrologic data: U.S. Geological Survey Professional Paper 434-E, 7 p. 
McCain, J. F., 1974, Progress report on flood-frequency synthesis for smal1 streams in Alabama: Alabama Highway Research, HPR70, 109 p.

Philip, J. R., 1954, An infiltration equation with physical significance: Soil Science Society of America Proceedings, v. 77, p. 153-157.

Thomas, D. M., and Benson, M. A., 1970, Generalization of streamflow characteristics from drainage-basin characteristics: U.S. Geological Survey WaterSupply Paper 1975, 55 p.

Water Resources Council, 1976, Guidelines for determining flood-flow frequency: U.S. Water Resources Council Bulletin 17, 26 p.

Wibben, H. C., 1976, App1ication of the U.S. Geological Survey rainfa11-runoff simulation model to improve flood-frequency estimates on sma11 Tennessee streams: U.S. Geological Survey Water-Resources Investigations 76-120, $53 \mathrm{p}$. 
Table 1.--Model parameters and variables and their application in the modeling process

\begin{tabular}{|c|c|c|c|}
\hline Parameter & Varlable & Units & Application \\
\hline BMSM---- & $-\cdots$ & Inches--- & $\begin{array}{l}\text { Soll-molsture storage at field capacity. Maximum value of } \\
\text { base moisture storage variable, } B M S .\end{array}$ \\
\hline RR-- - - - - & --ー-- - & $0.85 * \ldots$ & Proportion of dafly rainfall that infiltrates the soll. \\
\hline EVC----- & ------- & $0.65-0.75 *$ & Pan evaporation coefficient. \\
\hline DRN- - - & ----- - & $1.0 * \cdots$ & $\begin{array}{l}\text { Drainage factor for redistribution of saturated moisture } \\
\text { storage, } S M S \text {, to base (unsaturated) molsture storage, } \\
B M S \text {, as a fraction of hydraulic conductivity, KSAT. }\end{array}$ \\
\hline--- & BMS---- & Inches--- & $\begin{array}{l}\text { Base (unsaturated) moisture storage in active soil column. } \\
\text { Simulates antecedent moisture content over the range } \\
\text { from wilting-point conditions, } B M S=0 \text {, to field capacity, } \\
B M S=B M S M \text {. }\end{array}$ \\
\hline 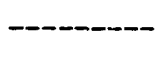 & SMS----- & Inches---- & $\begin{array}{l}\text { "Saturated" moisture storage in wetted surface layer } \\
\text { developed by infiltration of storm rainfall. }\end{array}$ \\
\hline --- - - - - & FR- - - & $\begin{array}{r}\text { Inches per } \\
\text { hour- }\end{array}$ & $\begin{array}{l}\text { Infiltration capacity, a function of } K S A T, P S P, R G F, B M S M \text {, } \\
\quad S M S, B M S \text { (equation } 4 \text { ). }\end{array}$ \\
\hline KSAT----- & - - & $\begin{array}{r}\text { Inches per } \\
\text { hour--- }\end{array}$ & Hydraulic conductivity of "saturated" transmission zone. \\
\hline PSP----- & 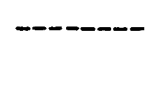 & Inches---- & $\begin{array}{l}\text { Combined effects of molsture deficit, as indexed by } E M S \text {, } \\
\text { and capillary potential (suction) at the wetting front } \\
\text { for } B M S \text { equal to field capacity, } B M S M \text {. }\end{array}$ \\
\hline RGF---- & ------- & --m-n- & $\begin{array}{l}\text { Ratio of combined effects of moisture deficit, as indexed } \\
\text { by } B M S \text {, and caplllary potential (suction) at wetting } \\
\text { front for } B M S=0=\text { wilting point, to the value associated with } \\
\text { field capacity conditions, } P S P \text {. }\end{array}$ \\
\hline KSW--- - - & $---\infty-\infty$ & Hours----- & Linear reservoir recession coefficient. \\
\hline$T C-\boldsymbol{n - n - m}$ & --ー---- & Minutes--- & Time base (duration) of triangular translation hydrograph. \\
\hline$T P / T C---$ & --m-- - & $0.5 *-\cdots$ & $\begin{array}{l}\text { Ratio of time to peak of triangular translation hydrograph } \\
\text { to duration of translation hydrograph, } T C \text {. }\end{array}$ \\
\hline$-\cdots$ & SW-- - & Inches--- & Linear reservoir storage. \\
\hline
\end{tabular}

*The parameters $R R$ and $E V C$ are highly "interactive" and were constrained. $R R$ was arbitrarily assigned the value of 0.85 , and $E V C$ values were computed as the factor required to scale available local average annual pan evaporation to equivalent values of average annual lake evaporation as estimated from figure 2, "Evaporation maps for the United States," Technical Paper No. 37, U.S. Department of Commerce, 1959. The parameters $D R N$ and $T P / T C$ have little influence on model results. $D R N$ was arbitrarily assigned a value of 1.0 , and the shape of an isosceles triangle assumed for the translation hydrograph. 
Table 2.--Long-term recording rainfall sites used in study

[NS, number of storm events; NWY, number of water years]

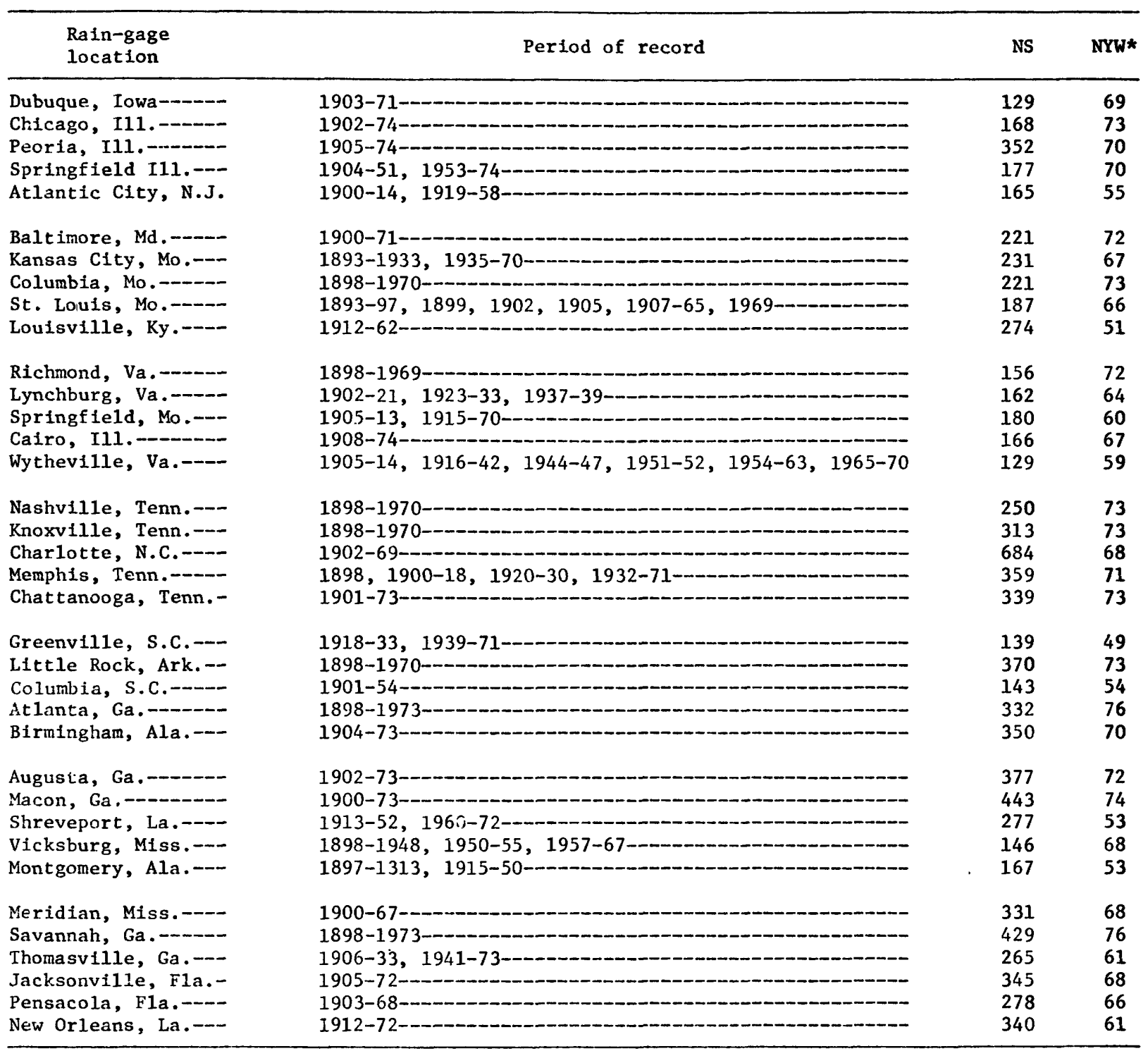

*Annual flood synthesis requires daily precipitation values during nonstorm moisture accounting periods and 5-minute rainfall intensities during storm events ( $f$ ig. 1 ). A "storm event" is a subjective definition and may comprise several hours of intense rainfall occurring within a period of several consecutive days. Dates of storm events were identfied by U.S. Geological Survey personnel by analysis of available precipitation summaries. The majority of the storm event data were coded from original recorder charts by the National Climatic Data Center, NOAA, Asheville, N.C. In some instances copies of original recorder charts were acquired and reduction made by U.S. Geological Survey personnel. Streamflow characteristics such as the arnual peak discharge, mean annual flow, and so forth, are typically reported on a water-year basis. The water year, October 1 through September 30 , is identified by the calendar year in which it ends. 


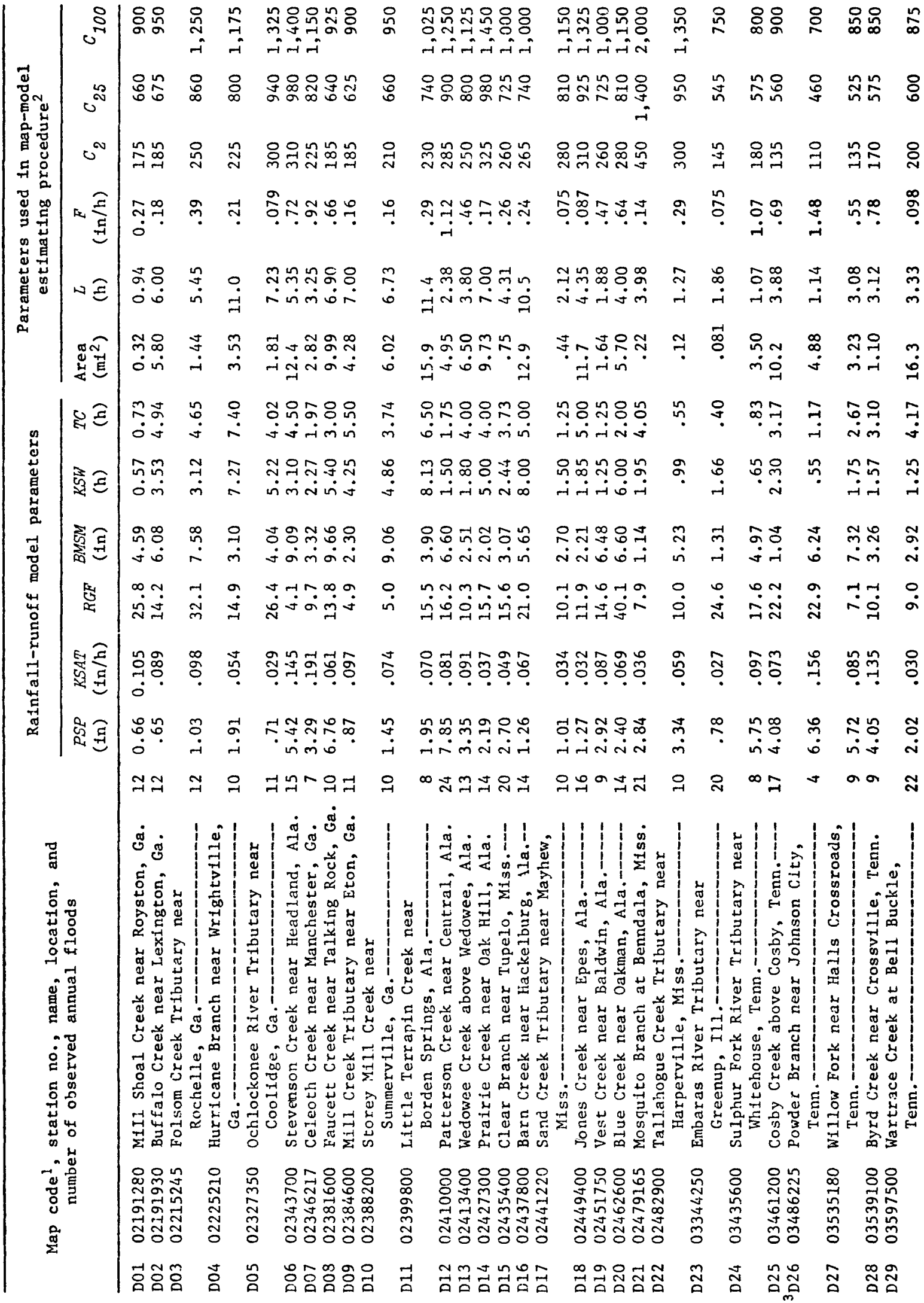




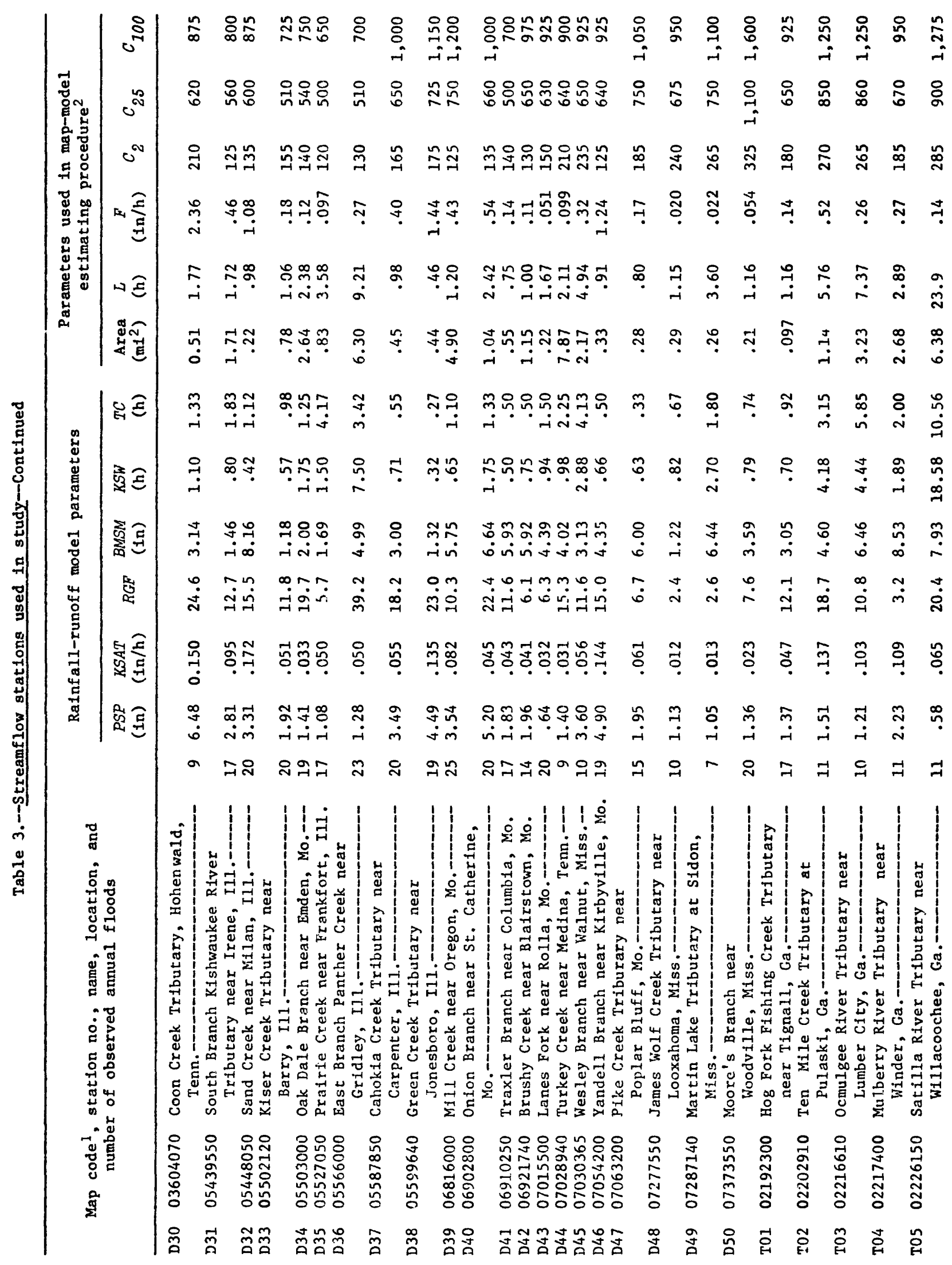




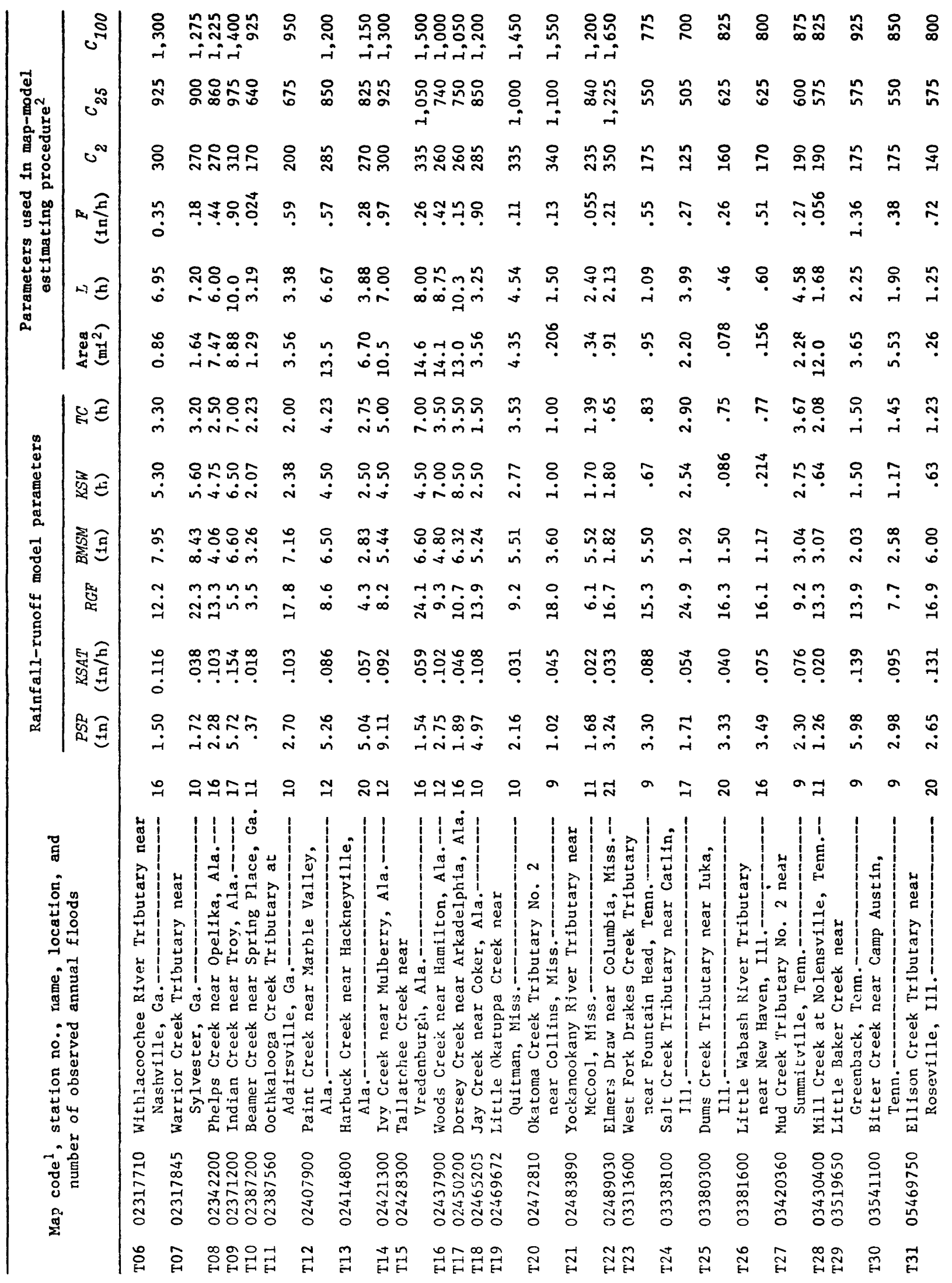




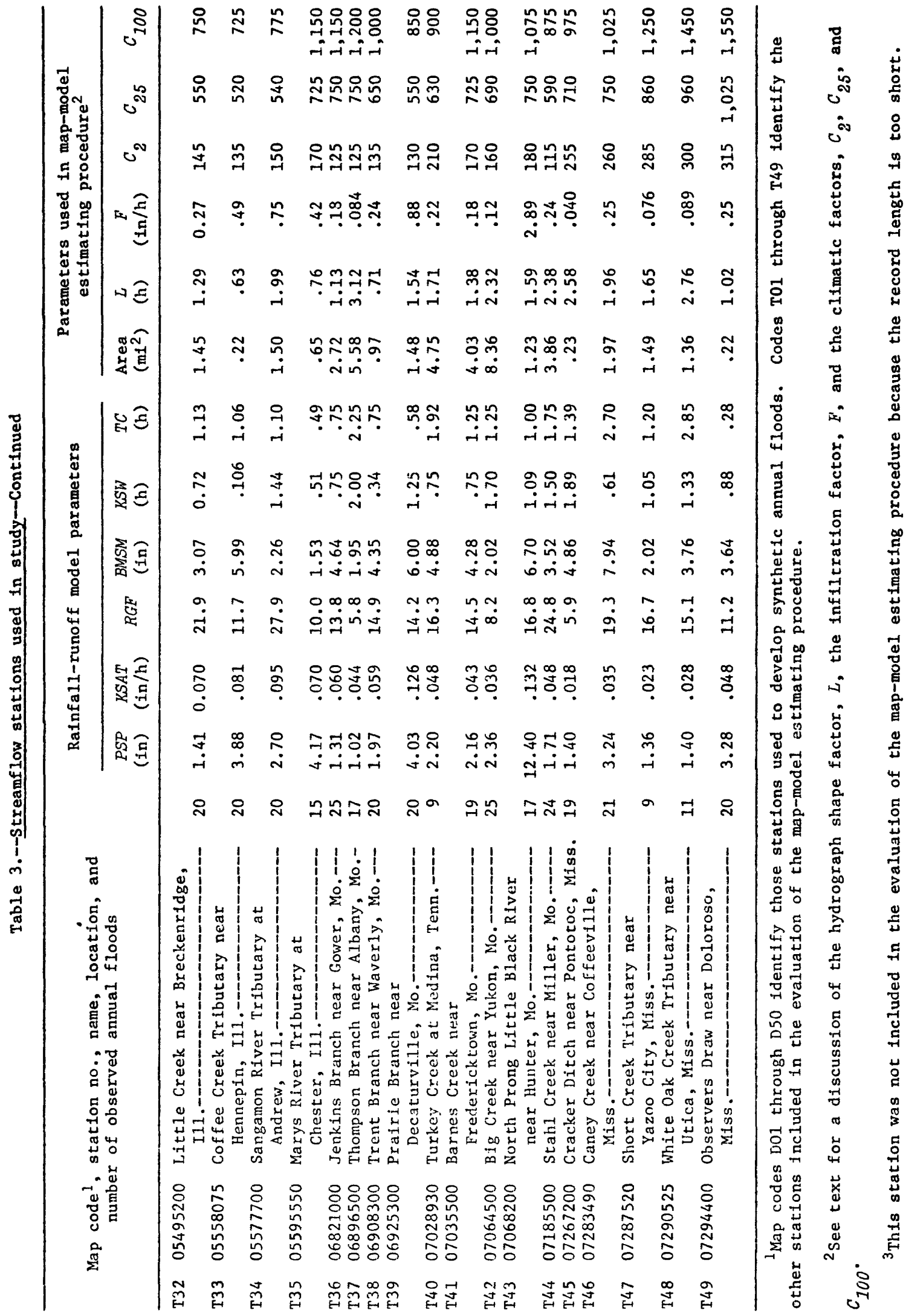




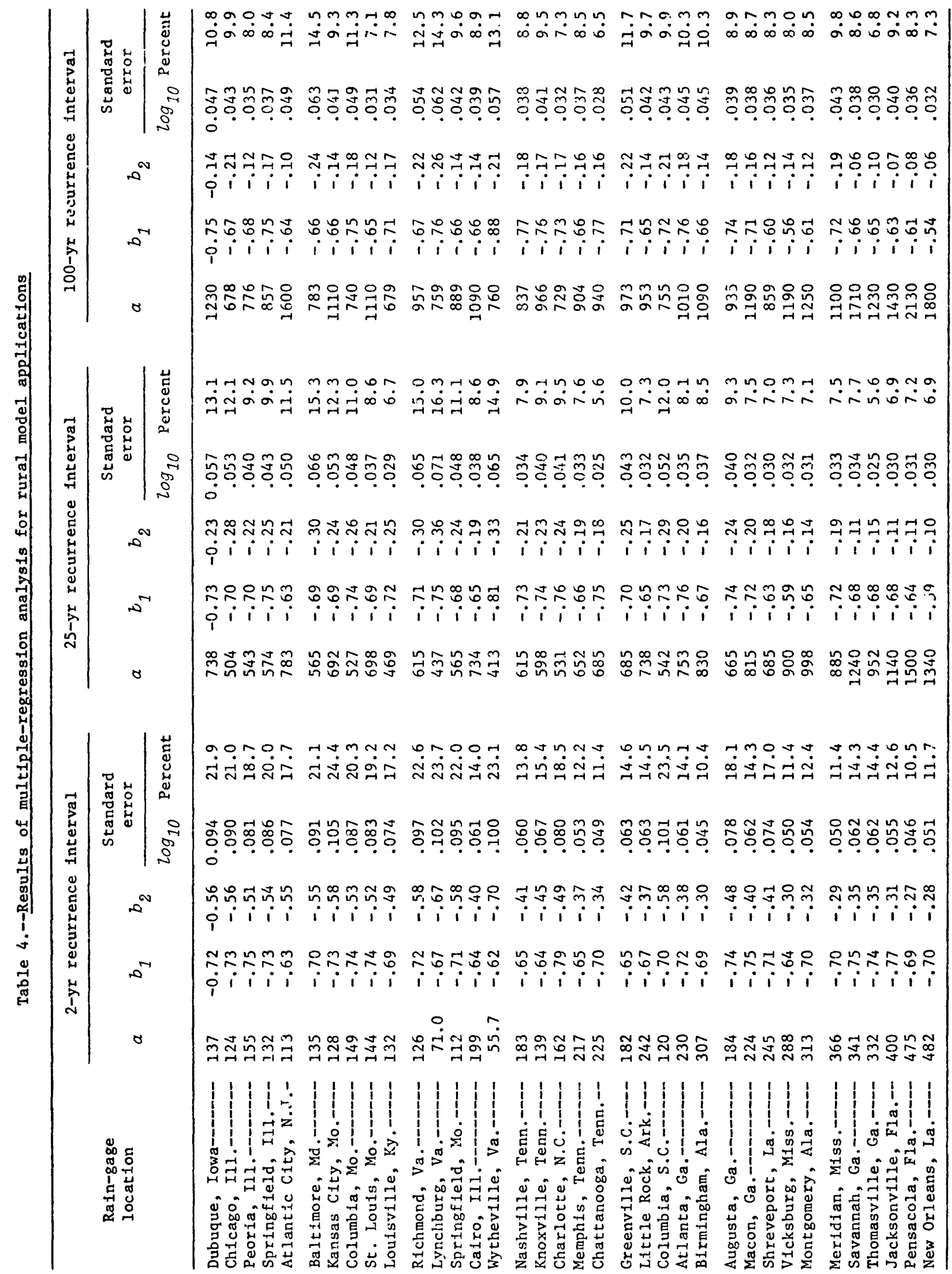




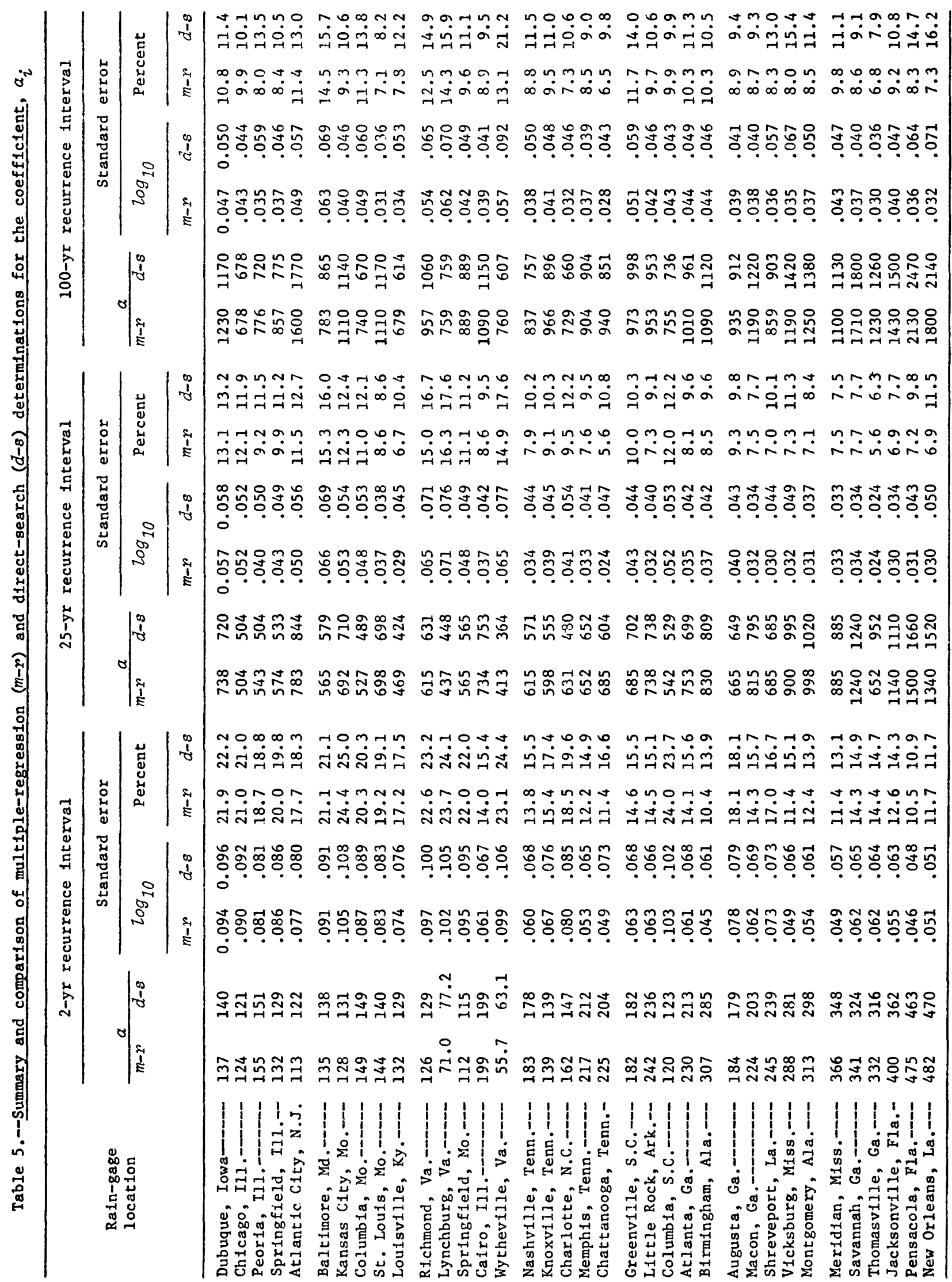




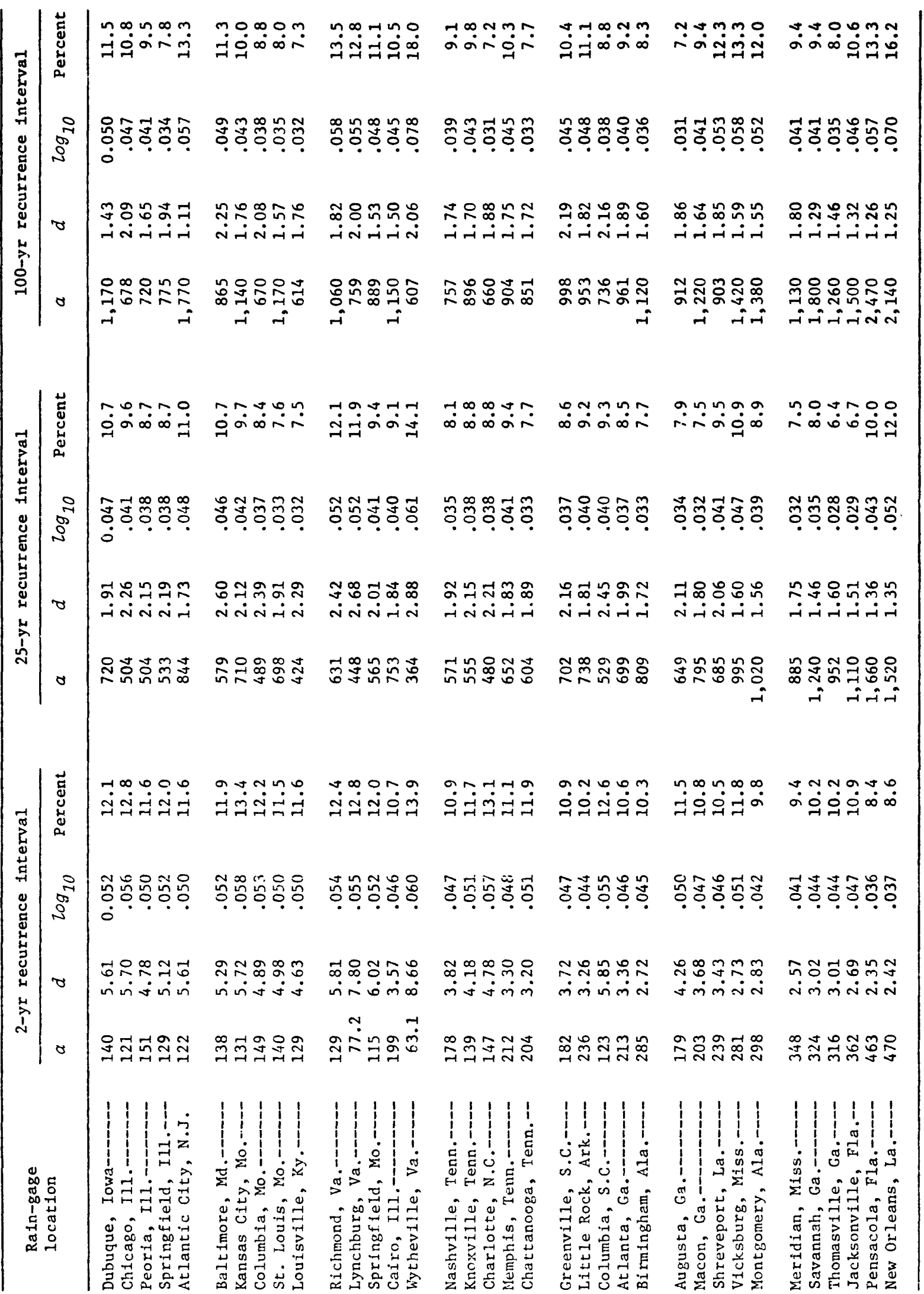




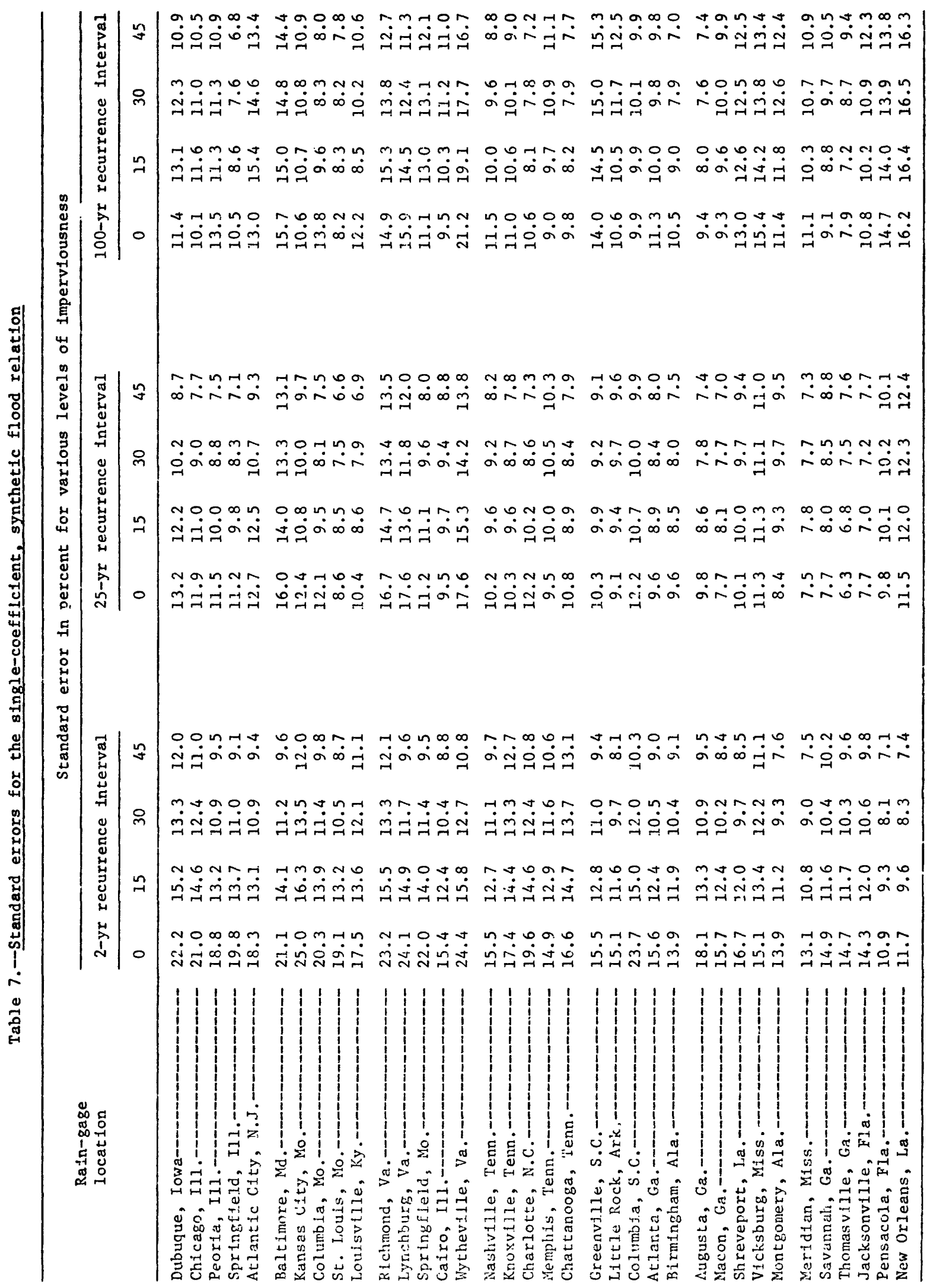

